https://helda.helsinki.fi

Development and application of an advection-dispersion model for data analysis of electromigration experiments with intact rock cores

\title{
Meng, Shuo
}

2020-05

Meng , S , Li , X , Siitari-Kauppi , M \& Liu , L 2020 , ' Development and application of an advection-dispersion model for data analysis of electromigration experiments with intact rock cores ' , Journal of Contaminant Hydrology , vol. 231 , 103618 . https://doi.org/10.1016/j.jconhyd.2020.103618

http://hdl.handle.net/10138/339433

https://doi.org/10.1016/j.jconhyd.2020.103618

cc_by_nc_nd

draft

Downloaded from Helda, University of Helsinki institutional repository.

This is an electronic reprint of the original article.

This reprint may differ from the original in pagination and typographic detail.

Please cite the original version. 


\section{Journal Pre-proof}

Development and application of an advection-dispersion model for data analysis of electromigration experiments with intact rock cores

Shuo Meng, Xiaodong Li, Marja Siitari-Kauppi, Longcheng Liu

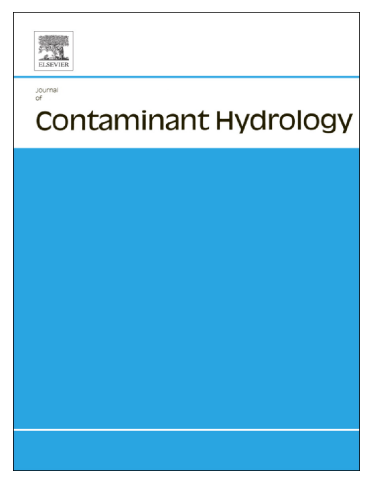

PII: $\quad$ S0169-7722(19)30160-3

DOI: $\quad$ https://doi.org/10.1016/j.jconhyd.2020.103618

Reference: $\quad$ CONHYD 103618

To appear in: Journal of Contaminant Hydrology

Received date: $\quad 23$ May 2019

Revised date: $\quad 8$ January 2020

Accepted date: $\quad 23$ January 2020

Please cite this article as: S. Meng, X. Li, M. Siitari-Kauppi, et al., Development and application of an advection-dispersion model for data analysis of electromigration experiments with intact rock cores, Journal of Contaminant Hydrology(2019), https://doi.org/10.1016/j.jconhyd.2020.103618

This is a PDF file of an article that has undergone enhancements after acceptance, such as the addition of a cover page and metadata, and formatting for readability, but it is not yet the definitive version of record. This version will undergo additional copyediting, typesetting and review before it is published in its final form, but we are providing this version to give early visibility of the article. Please note that, during the production process, errors may be discovered which could affect the content, and all legal disclaimers that apply to the journal pertain.

CC 2019 Published by Elsevier. 


\section{Development and application of an advection-dispersion model for data analysis of electromigration experiments with intact rock cores}



1. Department of Chemical E' $\mathrm{g}$..eering, KTH Royal Institute of Technology,

$\because "-10 \cup 44$ Stockholm, Sweden

2. Department of Th mistry - Radiochemistry, University of Helsinki,

D.C. Box 55, FI-000 14 Helsinki, Finland

*Corresponding author: Shuo Meng (shuom@kth.se) 


\begin{abstract}
An advection-dispersion model was developed for interpreting the experimental results of electromigration in granitic rock cores. The most important mechanisms governing the movement of the tracer ions, i.e. electromigration, electroosmosis and dispersion were taken into account by the advection-dispersion model, but the influence of aqueous chemistry was ignored. An analytical solution in the Laplace domain was derived and then applied to analyse the measured results of a series of experiments, performed in an updated device with different applied voltages. The modelling results suggested that both studied tracers, i.e. iodide and selenite, are effectively non-sorbing in the intact rock investigated. The effective diffusivities and formation factors evaluated from the model were also found to be in good agreement with data reported in literature and the associated uncertainties are much smaller than those obtained from the classical ideal plug-flow model, which accounts only $\boldsymbol{\prime}^{\mathbf{r}}$ the dominant effect of electromigration on ionic transport. To explore further $\mathrm{r}$ ow the quality of parameter identifications would be influenced by neglect of aqueous $\operatorname{ch}^{n m_{L_{L}}^{*}-y}$, a reactive transport model was also implemented, which may be regarded as a multi-c >mp snent version of the advectiondispersion model. The analysis showed that the advection tispersion model works equally well as the reactive transport model but requires much les computational demanding. It can, therefore, be used with great confidence to interpret the . ..perimental results of electromigration for studies of diffusion and sorption behavior of rar.: nuclides in intact rock cores.
\end{abstract}

Keywords: Electromigration experiments, i ea $_{\mathfrak{a}}$ plug-flow model, advection-dispersion model, reactive-transport model, parameter identí icat on. 


\section{Introduction}

In many countries, the spent nuclear fuel is planned to be deposited in deep geological repositories (Boyle and Meguid, 2015; Gylling et al., 1999; Posiva, 2012; Vomvoris et al., 2013; Wang, 2010). It is, in the Swedish KBS-3 concept, encapsulated in copper canisters, surrounded by bentonite clays, and buried into crystalline bedrocks at a depth of about 500 meters underground (SKB, 2011). The use of the multiple engineered and natural barriers aims to isolate radionuclides embedded in the spent nuclear fuel from biosphere as far as possible.

However, in the case of a canister failure, the radionuclides could first be released from the canister and then continue to move through conductive fractures by convection of groundwater flow. They might also be withdrawn from flowing water, entering into surrounding bedrock by diffusion, and further be retarded onto pore surfaces hy sorption. Due to the low permeability and large internal surfaces of the crystalline rocks, lla ix diffusion and sorption are by far the most important mechanisms of radionuclide retardation. (N'eretnieks, 1980).

To determine accurately the diffusion and sorptior. nroperties of radionuclides, extensive studies have been performed by block scale diffusion e. pu in.ents (García-Gutiérrez et al., 2006; Ikonen et al., 2016), through-diffusion experiments ( $\mathrm{N}_{1}$ - $\varsigma_{1}$ et al., 2010; Tachi et al., 2015) and batch sorption experiments (Li et al., 2018; Soderlund ct al., 2016a, 2016b). Among these experimental methods, batch sorption experiments ( $r$ r wford, 2010) can only be used to evaluate the sorption properties of radionuclides on crusi. 'd rucks. The obtained $K_{\mathrm{d}}$ values may, therefore, be different from that of intact rock as $\mathrm{cr}^{\prime}$ shi $\mathrm{g}$ increases significantly the specific surface area of the rock samples and may give access . otherwise isolated pores. By comparison, block scale- or through-diffusion experimen can be used to determine additionally the diffusion properties of radionuclides. The parar c ${ }^{+e}$ ers evaluated from these experiments are generally more reliable since the rock samples were nc exposed to sawing and crushing artefacts. However, it is rather time-consuming to perform ex eriments with intact rock cores, often taking e.g. several years (Ikonen et al., 2016), due ${ }^{+}$) th very low porosity of crystalline rocks (Möri et al., 2003).

The experimental tiı'e (an, nevertheless, be reduced considerably by applying either hydraulic pressure in per :ola ion tests, or electrical field in electromigration experiments. Since the rock has a low per recusity, an extremely high hydraulic pressure is commonly applied to move the pore water quic ly (Maes et al., 1999; Mitchell and Soga, 2005). By contrast, only a small electric field is required in electromigration experiments, making this approach more efficient and feasible (Mitchell, 1993). As a result, it has widely been used to accelerate the transport of charged ions in various media, such as in clay (Beauwens et al., 2005; Maes et al., 1999, 2002), in semiconductors (Heinemann and Frischat, 1993; Nebauer et al., 1977), in concrete (McGrath and Hooton, 1996) and also in intact rock cores (André et al., 2009; Löfgren and Neretnieks, 2006; Puukko et al., 2018), with different setups.

By comparison, the electromigration device of Löfgren and Neretnieks (2006) has a special advantage in that it minimizes the influence of water electrolysis on ionic transport, as illustrated in Fig. 1. It has been used successfully to estimate the formation factors of crystalline rocks (Löfgren and Neretnieks, 2006), and also the diffusion and sorption properties of iodide and cesium in granite (André et al., 2009). However, some improvements of the device can still be made. As detailed in our companion paper (Li et al., 2019), a potentiostat is now introduced 
into the system. It replaces the normal power source, and also enables to impose automatically a constant voltage over the rock sample and monitor the evolution of ionic current flowing through the system. In addition, a small amount of $\mathrm{NaHCO}_{3}$ is added into the background electrolyte of $\mathrm{NaCl}$, making it possible to stabilize the $\mathrm{pH}$ of the solution at $\sim 8.5$.

Using the updated device, a feasibility study was performed for both iodide and selenite tracers with applied voltages of $2 \mathrm{~V}$ and $4 \mathrm{~V}$ over a crystalline rock sample of length $1.12 \mathrm{~cm}(\mathrm{Li}$ et al., 2019). The experimental results, expressed as the evolution of the tracer concentration in the recipient chamber, showed a clear breakthrough time before which the concentration remained at the background level and after which the concentration increased gradually, in all cases studied. Moreover, comparison of the experimental results also showed a larger breakthrough time and a smaller increase in the rate of the concentration change when $2 \mathrm{~V}$ instead of $4 \mathrm{~V}$ was applied over the rock sample, in both $\mathrm{I}^{-}$and $^{2} \mathrm{O}_{3}{ }^{2-}$ experiments. All these suggest that the updated device of electromigration worked we' 1 se that all the tracer ions have migrated through the rock sample by connected micropore not, $\boldsymbol{r}_{\mathrm{i}}$, and that the experimental results can be used confidently to evaluate the diffusion and : orpt on properties of the tracer ions, with suitable selection of the models.

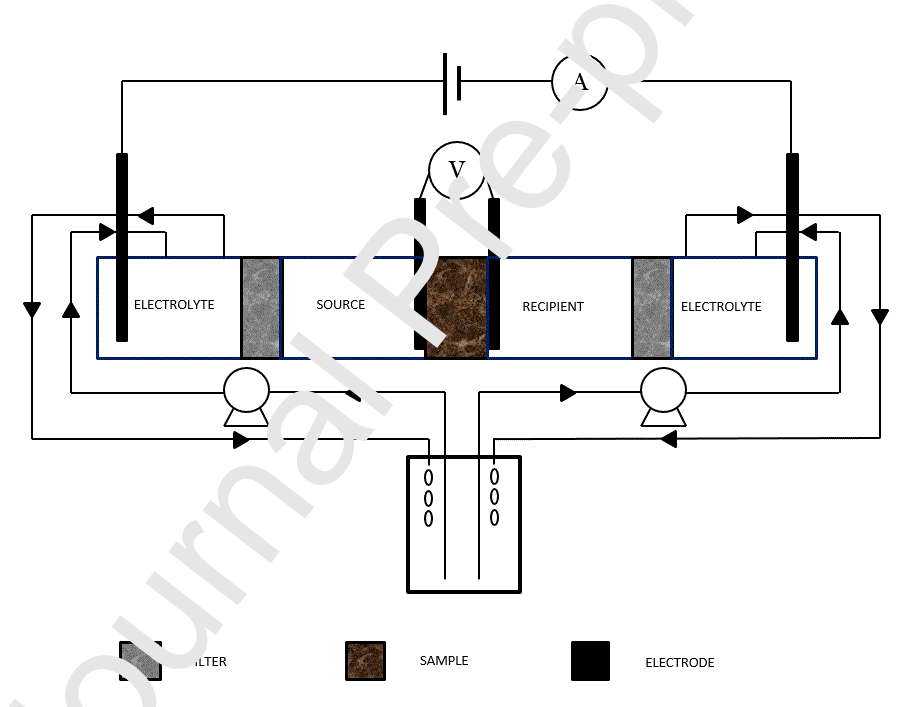

Fig. 1: Schematic stup for the electromigration experiments (Löfgren and Neretnieks, 2006).

Traditionally, the results of electromigration experiments are commonly interpreted by the ideal plug-flow model (André et al., 2009; Löfgren and Neretnieks, 2006) mainly due to the availability of its analytic solution and the simplicity of its practical use. This model accounts, however, only for the effect of electromigration on ionic transport whereas the contributions of electroosmosis and dispersion are entirely neglected. As a result, only a small portion of the latetime breakthrough curve, over which the tracer concentration increases seemingly in a constant rate, can be used for data analysis. This inevitably causes trouble or difficulty in the cases when proper determination of the late-time period becomes problematic. In addition, the ideal plugflow model used by André et al. (2009) also assumed that the tracer flux into the rock sample has been constant during the experiment and that the rock sample has been fully in equilibrium with the tracer ions at the source solution at the breakthrough time, in order to estimate the $K_{\mathrm{d}}$ value conveniently. This is far from realistic, not to mention the simplification that the tracer concentration in the source chamber was assumed to remain constant all the time. 
To address all the problems associated with the ideal plug-flow model, a general advection-dispersion model was developed in this study that accounts for the most important mechanisms governing the movement of the tracer ions in the electromigration device, i.e., electromigration, electroosmosis and dispersion. It looks similar to that of Maes et al. (1999) in the governing equation, but subject to different boundary conditions. As a result, the tracer concentration in the recipient chamber can be expressed analytically only in the Laplace domain. This requires, then, a numerical algorithm of inverse Laplace transform (De Hoog et al., 1982) to be applied for data analysis of the experimental results. Nevertheless, the advection-dispersion model is quite general in applications because it reduces to the ideal plug-flow model when dealing with a limiting case where the effect of both electroosmosis and dispersion can be neglected. In addition, the advection-dispersion model allows the effective diffusivity and the $K_{\mathrm{d}}$ value (equivalently, the retardation factor) to be evaluated on se at a time, instead of each separately as the ideal plug-flow model does, by fitting its nume: cal solution to all the data points of the measured breakthrough curve.

When applied for practical use in the specific case $: w_{1}$ studied (Li et al., 2019), the results of the advection-dispersion model suggested that $L$ th lodide and selenite are effectively non-sorbing in the intact rock investigated and that the inl lence of anionic exclusion, if any, is negligible. The obtained effective diffusivities and for $n$ on factors were also found to be in good agreement with data reported in literature (^ndré el al., 2009; Ohlsson and Neretnieks, 1997; Vecernik et al., 2013; Löfgren and Neretnit's, : 005; Thunehed, 2005). More importantly, it was shown that the uncertainties associa ${ }^{+\sim} d$, ith parameter identifications are much smaller than those obtained from the ideal pl: $\sigma_{-} \mathrm{f}^{1} \mathrm{Jw}$ model, due mainly to consideration of the dispersion mechanism into the model.

The advection-dispersion mor.c duas not, however, account for any speciation of the aqueous solution and ionic equilihrı $m$ as if the background electrolyte does not exist. To explore how the neglect of aqueo' $s c_{1}$ 'mistry would influence data analysis of the experimental results, we also formulated a re ctiv transport model in a way that may be regarded as a multicomponent version of the au recion-dispersion model. The implementation of the reactive transport model in a simple $y+r$ asonable case, where it is possible to introduce the concept of a modified electric potenti 1,1 . trivial with the help of the PHREEQC module (Appelo, 2017). When used to interpre, ou results of electromigration experiments ( $\mathrm{Li}$ et al., 2019), it was substantiated that the $\mathrm{e}^{+}$fect of aqueous chemistry is actually unimportant compared to electromigration, electroosmosis and dispersion in governing ionic transport in electromigration experiments. One may, therefore, convincingly use the advection-dispersion model to interpret the experimental results, giving reliable evaluations of the diffusion and sorption properties of the tracer ions in intact rock cores.

Unless otherwise required, the advection-dispersion model should be applied in the first place because it has a lower level of sophistication and less computational demanding than the reactive transport model. Due mainly to this reason, we put the focus of the paper on the development and application of the advection-dispersion model and organize the paper as follows. In Section 2, the advection-dispersion model is formulated in detail, including discussion of the most important mechanisms governing ionic transport in the electromigration device. This is, then, followed with derivation of the general transient solution in the Laplace domain and the simple analytical solution in the limiting case that the ideal plug-flow model 
concerns. In Section 3, the methodologies for data analysis of our experimental results (Li et al., 2019) with different models are detailed. Although the focus is on the discussion of application of the advection-dispersion model, the use of the ideal plug-flow model (André et al., 2009) is taken as the starting point for parameter identification. The aim is to facilitate understanding the difference of the two models and their merit and demerit in interpretation of the experimental results. To examine further the accuracy of the parameters obtained by the advection-dispersion model, the reactive transport model is, then, briefed with a short discussion of the influence of aqueous chemistry on the estimated results. The conclusions are drawn in Section 4 at the end of the paper.

\section{Model development}

As illustrated in Fig. 1 and also detailed in our companion pane (I et al., 2019), the key of the experimental setup is to isolate the electromigration cell, cc nsis ing of the source chamber, the rock sample and the recipient chamber, from surrounding by positioning two rock filters. This enables to minimize the influence of electrolysis of var in the electrode chambers on the chemistry of tracer solutions and also the loss of trace in is into the electrode chambers. As a result, we may take the electromigration cell as a clnsıd syıtem, in which a constant voltage has been applied over the rock sample.

Since the electromigration cell is $f$ sse tiaıy the same as the classical through-diffusion cell (Löfgren, 2004; Ohlsson, 2001), excep that an electric field is now applied, we may also write the equation of continuity for the dilute uracer under consideration within the rock sample as (Appelo, 2017)

$$
\varepsilon_{\mathrm{TS}} \frac{\partial c}{\partial t}=-\frac{\partial N^{\mathrm{e}}}{\partial x}-\frac{\partial q}{\partial t}
$$

where $c(x, t)$ is the tracer cor - er tration in the solution at position $x$ at time $t, \varepsilon_{\mathrm{TS}}$ is the porosity of the rock sample avail tble for both transport and storage of tracer ions (André et al., 2009; Löfgren, 2004), $N^{\mathrm{e}}$ is 'e ufective mass flux; and $q$ is the tracer concentration in the solid, which changes as a resilt of mineral reactions, sorption and ion exchange etc. (Appelo, 2017). For ease of reference, a complete list of symbols and dimensions are also given at the end of the paper.

When only linear sorption isotherm is considered for the solid phase, it simplifies to

$$
\varepsilon_{\mathrm{TS}} R \frac{\partial c}{\partial t}=-\frac{\partial N^{\mathrm{e}}}{\partial x}
$$

with the retardation factor $R$ given by,

$$
R=1+\frac{\rho K_{\mathrm{d}}}{\varepsilon_{\mathrm{TS}}}
$$


where $\rho$ is the dry bulk density of the measured rock sample; $K_{\mathrm{d}}$ is the distribution coefficient.

Equation (2) describes, then, the mass balance of tracer ions in the rock sample, along with the initial condition,

$c(x, 0)=0$

and the boundary conditions

$c(0, t)=c_{\mathrm{L}}(t)$

and

$c(L, t)=c_{\mathrm{R}}(t)$

where $L$ is the length of the rock sample; $c_{\mathrm{L}}$ and $c_{\mathrm{R}}$ are the $\mathrm{t}$ 7cer concentration in the source and recipient chambers, respectively.


continuously stirred tanks, due to the fact that magnatic stir.ers have been applied all the time in the experiments. As a result, the evolution of $c_{\mathrm{L}} c_{\mathrm{ln}}$ be determined in terms of a macroscopic mass balance over the source chamber as,

$V_{\mathrm{L}} \frac{\mathrm{d} c_{\mathrm{L}}}{\mathrm{d} t}=-\left.A N^{\mathrm{e}}\right|_{\mathrm{x}=0}$

along with the initial condition:

$c_{\mathrm{L}}(0)=c_{0}$

where $V_{\mathrm{L}}$ is the volume of thc sr urce chamber; $A$ is the cross-sectional area of the rock sample; $c_{0}$ is the initial solute cor sent ation in the source chamber.

Likewise, the char ge of $c_{\mathrm{R}}$ with time can be described by a macroscopic mass balance over the recipient chamber as,

$V_{\mathrm{R}} \frac{\mathrm{d} c_{\mathrm{R}}}{\mathrm{d} t}=\left.A N^{\mathrm{e}}\right|_{\mathrm{x}=\mathrm{L}}$

along with the initial condition:

$c_{\mathrm{R}}(0)=0$

where $V_{\mathrm{R}}$ is the volume of the recipient chamber.

At this point, the effective mass flux $N^{\mathrm{e}}$ has not been explicitly expressed yet. In the traditional through-diffusion experiment (Löfgren, 2004; Ohlsson, 2001), we know that it is 
given simply by the one-dimensional form of Fick's first law of diffusion. For the electromigration cell under study, however, it involves both convection and dispersion as a result of application of an electric field (as detailed in Appendix A) and can generally be written as

$$
N^{\mathrm{e}}=c v_{\mathrm{c}}^{\mathrm{e}}-D^{\mathrm{e}} \frac{\partial c}{\partial x}
$$

where $v_{\mathrm{c}}^{\mathrm{e}}$ is the effective convection velocity composed of both drift (electromigration) speed, $v_{\mathrm{em}}^{\mathrm{e}}$ and electroosmostic velocity, $v_{\mathrm{eo}}^{\mathrm{e}}$, and $D^{\mathrm{e}}$ is the effective dispersion coefficient, which can be approximated by (Beauwens et al., 2005),

$$
D^{\mathrm{e}}=\alpha v_{\mathrm{c}}^{\mathrm{e}}+D_{\mathrm{m}}^{\mathrm{e}}
$$

where $\alpha$ is the dispersion length and $D_{\mathrm{m}}^{\mathrm{e}}$ is the effective molecul ir $\mathrm{d}_{1}$ 'fusion coefficient. also write

When the expressions of both $v_{\mathrm{em}}^{\mathrm{e}}$ and $v_{\mathrm{eo}}^{\mathrm{e}}$, given in . $1 \mathrm{pp}$ ndix $\mathrm{A}$, are introduced, we can

$$
N^{\mathrm{e}}=-c\left(\mu_{\mathrm{eo}}^{\mathrm{e}}+\frac{D_{\mathrm{m}}^{\mathrm{e}} z e}{k_{\mathrm{B}} T}\right) \frac{\partial \psi}{\partial x}-D^{\mathrm{e}} \frac{\partial c}{\partial x}
$$

and

$$
D^{\mathrm{e}}=-\alpha\left(\mu_{\mathrm{eo}}^{\mathrm{e}}+\frac{D_{\mathrm{m}}^{\mathrm{e}} z e}{k_{\mathrm{B}} T}\right) \frac{\partial \psi}{\partial x}+D_{\mathrm{m}}^{\mathrm{e}}
$$

where $\mu_{\mathrm{eo}}^{\mathrm{e}}$ is the effective electroos notic mobility, $k_{\mathrm{B}}$ is the Boltzmann constant, $T$ is the absolute temperature, $z$ is the "llence of the tracer ions, $e$ is the electron charge, and $\psi$ is the electric potential.

Clearly, both $N^{f}$ an $1 D^{\mathrm{e}}$ are potential-gradient-dependent, which in reality varies spatially and temporal, as $u$ result of keeping electroneutrality of ions in the pore space of the rock sample. However, it only changes slightly over a short time in the beginning of experiments, as justified by the simulation results of PHREEQC (Appelo, 2017). We may, therefore, assume that the potential gradient is simply constant throughout the rock sample.

Under this simplification, the coupled system of governing equations, i.e. Eqs. (2), (7) and (9), along with the initial and boundary conditions, can readily be solved by applying the Laplace transform method. As detailed in Appendix B, the Laplace transformed solution of $c_{\mathrm{R}}$ is found to be,

$$
\bar{c}_{\mathrm{R}}=-\frac{S \frac{\operatorname{csch}(S)}{\mathrm{Pe}}}{\left[\frac{1}{2}+\beta_{\mathrm{L}} s+S \frac{\operatorname{coth}(S)}{\mathrm{Pe}}\right]\left[\frac{1}{2}-\beta_{\mathrm{R}} s-S \frac{\operatorname{coth}(S)}{\mathrm{Pe}}\right]+\left[S \frac{\operatorname{csch}(S)}{\mathrm{Pe}}\right]^{2}} \exp \left(\frac{\mathrm{Pe}}{2}\right) \beta_{\mathrm{L}} c_{0}
$$


where $s$ is the Laplace variable, $S$ is a $s$-dependent variable, Pe is the Péclet number, $\beta_{\mathrm{L}}$ and $\beta_{\mathrm{R}}$ are the relaxation times of the source and recipient chambers, respectively.

Application of a numerical algorithm (De Hoog et al., 1982) on Eq. (15) allows, then, to numerically transform the solution back to the time domain. The result would be the breakthrough curve of the tracer ions in the recipient chamber, under coupling action of electromigration, electroosmosis, and dispersion.

In the limiting case as $\mathrm{Pe} \rightarrow \infty$ or equivalently $D^{\mathrm{e}} \rightarrow 0$, i.e. when the dispersive mass transfer is entirely negligible compared to convection, the analytical solution given in Eq. (15) reduces to (see Appendix $\mathrm{C}$ for detail),

$\bar{c}_{\mathrm{R}}=\frac{c_{0}}{\beta_{\mathrm{R}}} \frac{1}{\left(s+\frac{1}{\beta_{\mathrm{L}}}\right) s} \exp \left(-\tau_{\mathrm{A}} s\right)$

where $\tau_{\mathrm{A}}$ denotes the characteristic advection time, definea $n$ Appendix B.

The inverse Laplace transform for $\bar{c}_{\mathrm{R}}$ immediately IVes (Abramowitz and Stegun, 1965),

$c_{\mathrm{R}}=c_{0} \frac{\beta_{\mathrm{L}}}{\beta_{\mathrm{R}}}\left\{1-\exp \left[-\frac{1}{\beta_{\mathrm{L}}}\left(t-\tau_{\mathrm{A}}\right)\right]\right\} u\left(t-\tau_{\mathrm{A}}\right)$

where $u(t)$ is the Heaviside step function.

Since, in general, the experin er " ${ }^{1}$ period is often much shorter than the relaxation time of the source chamber, i.e., $t \ll \beta_{\mathrm{I}}$, he uncated Taylor expansion of the exponential function to the second term (Abramowitz and. Ttegun, 1965) allows us to write,

$c_{\mathrm{R}} \approx \frac{c_{0}}{\beta_{\mathrm{R}}}\left(t-\tau_{\mathrm{A}}\right) u\left(t-\tau_{\mathrm{A}}\right)$

This is the simplı"ed solution of the ideal plug-flow model, which suggests essentially that the tracer concentrauon in the recipient chamber increases in a constant rate at time $t>\tau_{\mathrm{A}}$. Mainly for this reason, it has been widely applied in the interpretation of experimental results of electromigration (André et al., 2009; Löfgren and Neretnieks, 2006).

\section{Experimental results and data analysis}

As discussed in our companion paper ( $\mathrm{Li}$ et al., 2019), a series of electromigration experiments has been performed for both iodide and selenite using an updated device with detailed setup given in Table 1. 
Table 1: The model data obtained from electromigration experiments.

\begin{tabular}{|c|c|c|}
\hline \multicolumn{3}{|l|}{ Experimental set-up } \\
\hline $\begin{array}{l}\text { Source/Recipient chamber } \\
\text { volume }\end{array}$ & $\begin{array}{c}\text { Diameter of the source and recipient } \\
\text { chambers }\end{array}$ & Working temperature \\
\hline $152 \mathrm{ml}$ & $5 \mathrm{~cm}$ & $\sim 25^{\circ} \mathrm{C}$ \\
\hline \multicolumn{3}{|l|}{ Rock } \\
\hline Length & Diameter of the rock sample & Porosity of the rock sample \\
\hline $1.12 \mathrm{~cm}$ & $5 \mathrm{~cm}$ & $0.7 \%$ \\
\hline \multicolumn{3}{|l|}{ Background electrolyte } \\
\hline $\mathrm{pH}$ & $\mathrm{NaCl}$ concentration & $\mathrm{NaHCO}_{3}$ concentration \\
\hline$\sim 8.5$ & $0.2 \mathrm{M}$ & $0.002 \mathrm{M}$ \\
\hline \multicolumn{3}{|l|}{ Tracer and other information } \\
\hline $\mathrm{Na}_{2} \mathrm{SeO}_{3} / \mathrm{NaI}$ amount & $\begin{array}{c}\text { Effective electroosmotic mobility, } \mu_{\mathrm{eo}}^{\mathrm{e}} \\
0\end{array}$ & $\begin{array}{c}\text { El ctrical potential difference over } \\
\text { rock, } \Delta \psi \\
2 \text { and } 4 \mathrm{~V}\end{array}$ \\
\hline
\end{tabular}

It is noted that both the source chamber and + 1 e $r$ cipient chamber are much larger in volume than the rock sample, taken from Äspö undergı 'Ind laboratory (Li et al., 2019). This makes the concentration change nearly negligit ie in the source chamber and increase only slightly in the recipient chamber after the breakt' $r{ }^{\prime}$ ' $^{1}{ }^{1}$ time.

To avoid the influence of $\mathrm{pH}$ on $\mathrm{h} \mathrm{h}$ mistry of electrolyte solution, a small amount of $\mathrm{NaHCO}_{3}$ was added particularly into the bac'ground solution of $0.2 \mathrm{M} \mathrm{NaCl}$, mimicking both the ionic strength and the $\mathrm{pH}$ of the piactical in-situ conditions. This may help to keep the minerals of the rock sample unaltered, a. ${ }^{+}$additionally to minimize the disturbance of $\mathrm{H}^{+} \mathrm{or} \mathrm{OH}^{-}$ migrating from the electrode cham ${ }^{k}: \mathbf{r} i{ }^{\prime}, \mathrm{J}$ the tracer chambers, if any.

When the tracer of eithe $\mathrm{Na}_{2} \mathrm{NeO}_{3}$ or $\mathrm{NaI}$ were introduced in the source chamber, we also injected the same amount of $\mathrm{N}_{\mathrm{C}} \mathrm{C}_{1}$ into the recipient chamber. The aim is to balance the ionic strength of the solution thromy an the system in the beginning of experiments.

More importantı, w explore the extent to which electroosmosis has contributed to ionic transport, a series of tests at different electrical fields were performed as well using quinoxaline as the neutral tracer. The results suggest that the effect of electroosmosis could entirely be omitted in the experiments ( $\mathrm{Li}$ et al., 2019), i.e. one may safely set $\mu_{\mathrm{eo}}^{\mathrm{e}}=0$ in data analysis.

With this information, the experimental data can also be interpreted by the ideal plugflow model that considers barely the contribution of electromigration, and the reactive transport model that accounted only for electromigration and molecular diffusion.

\subsection{Application of the ideal plug-flow model}

Due to the simplicity of its solution, the ideal plug-flow model can readily be applied to give a quick estimate of the diffusion and sorption properties of the tracers (André et al., 2009; Löfgren 
and Neretnieks, 2006). The idea behind is that one only needs to make a linear regression of the data of the late-time breakthrough curve over which the tracer concentration increases seemingly in a constant rate, as suggested by Eq. (18). The intercept $t_{\mathrm{B}}$ of the regression line with the time coordinate gives, then, an estimate of the characteristic advection time, i.e. $t_{\mathrm{B}} \approx \tau_{\mathrm{A}}$, whereas the slope $\kappa$ of the regression line is an approximate of the rate of change of the tracer concentration in the recipient chamber, i.e. $\kappa \approx c_{0} / \beta_{\mathrm{R}}$. As a result, the definition of $\beta_{\mathrm{R}}$ in Eq. (B15) allows us to conclude that

$$
v_{\mathrm{c}}^{\mathrm{e}}=\frac{V_{\mathrm{R}} \kappa}{A c_{0}}
$$

It becomes identical to electromigration speed, $v_{\mathrm{em}}^{\mathrm{e}}$, ( $\mathrm{n}$ ! y under the condition that electroosmosis has been deemed to be unimportant in ionic transnntt. Since this is the case in our experiments, combination of Eqs. (A1) and (A2) gives dire tly for the effective diffusion coefficient $D_{\mathrm{m}}^{\mathrm{e}}$ :

$D_{\mathrm{m}}^{\mathrm{e}} \approx \frac{k_{\mathrm{B}} T}{z e E} \frac{V_{\mathrm{R}} \kappa}{A c_{0}}$

where we have used $E$ to denote the electric field ' $\mathrm{V}^{\prime} \mathrm{r}$ the rock sample, i.e. $E=\Delta \psi / L$.

It follows that the geometric for na on factor, as defined in Appendix A, can be estimated by

$F_{\mathrm{f}}=\frac{D_{\mathrm{m}}^{\mathrm{e}}}{D_{\mathrm{m}}}$

if the molecular diffusion coeff: ienı, $D_{\mathrm{m}}$, is known already.

Additionally, the avaı' abi ity of the breakthrough time $t_{\mathrm{B}}$ from the linear regression of the breakthrough curve and ne i pproximation of $t_{\mathrm{B}} \approx \tau_{\mathrm{A}}$ enables us to write the retardation factor as, when use is made or $\bar{F}_{4}$. (B7),

$$
R=\frac{v_{\mathrm{c}}^{\mathrm{e}} t_{\mathrm{B}}}{\varepsilon_{\mathrm{TS}} L}
$$

This expression implies that all the tracers could be considered as effectively non-sorbing as far as the following inequality holds,

$$
t_{\mathrm{B}} \leq\left.\tau_{\mathrm{A}}\right|_{\mathrm{R}=1}=\frac{\varepsilon_{\mathrm{TS}} L}{v_{\mathrm{c}}^{\mathrm{e}}}
$$

where $\left.\tau_{\mathrm{A}}\right|_{R=1}$ is the value of $\tau_{\mathrm{A}}$ in the case of $R=1$. 
Clearly, this approach can easily be applied for data analysis of the breakthrough curves at the price of many approximations and simplifications. The results should, therefore, better be used as an initial guess of $D_{\mathrm{m}}^{\mathrm{e}}, F_{\mathrm{f}}$, and $R$, respectively.

With this understanding, the measured data we obtained in the electromigration experiments ( $\mathrm{Li}$ et al., 2019) under different applied voltages were evaluated for both iodide and selenite tracers. The estimated values are summarized in Table 2 and Table 3, whereas the experimental results and the regression lines are given in Fig. 2 and Fig. 3, respectively.

Table 2: Evaluation of the breakthrough curves obtained with $\mathrm{NaI}$ as the tracer, using the ideal plug-flow model.

\begin{tabular}{|c|c|c|c|c|c|c|}
\hline$\Delta \psi(\mathrm{V})$ & $t_{\mathrm{B}}(\mathrm{hr})$ & $\kappa\left(\mu \mathrm{M} \mathrm{hr}^{-1}\right)$ & $D_{\mathrm{m}}^{\mathrm{e}}\left(\mathrm{m}^{2} \mathrm{~s}^{-1}\right)$ & $F_{\mathrm{f}}(-)$ & $\left.\tau_{\mathrm{A}}\right|_{R=1}(\mathrm{hr})$ & $R(-)$ \\
\hline 2.0 & 18.2 & 1.57 & $4.85 \times 10^{-14}$ & $2.38 \times 10^{-5}$ & 64.0 & 1.0 \\
\hline 4.0 & 11.0 & 7.31 & $1.13 \times 10^{-13}$ & $5.51 \times 10^{-5}$ & 1 1J.8 & 1.0 \\
\hline \multicolumn{3}{|c|}{ Linear regression results } & $8.83 \times 10^{-14}$ & $4.31 \times 10^{-5}$ & & \\
\hline
\end{tabular}

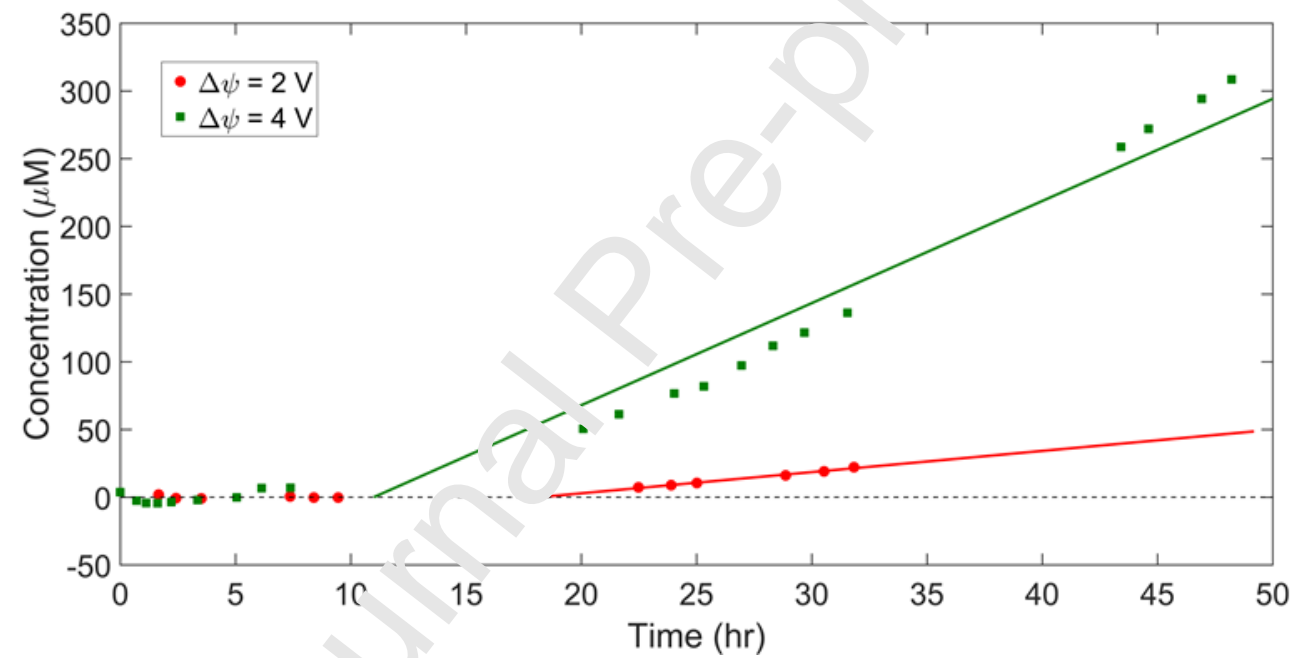

Fig. 2: The breakthrough curv ? of 1 ) dide with an applied voltage of $2 \mathrm{~V}$ or $4 \mathrm{~V}$ over the rock sample. Markers show the experimental data and thu lifu gives a linear regression of the late-time data.

Note, however, that we have used two methods to calculate $D_{\mathrm{m}}^{\mathrm{e}}$ for the tracers. The first method estimates $D_{\mathrm{m}}^{\mathrm{e}}$ directly from Eq. (20) using the evaluated $\kappa$ value for each of the cases studied. The results are, then, $\Delta \psi$-dependent. The second method makes use of the fact that $\kappa$ varies linearly with the electrical field $E$, as indicated by Eq. (20), and therefore $D_{\mathrm{m}}^{\mathrm{e}}$ can also be obtained from the slope of the linear relationship between $\kappa$ and $E$ of a series of experiments, as shown in Fig. 4. This would not only yield an $\Delta \psi$-independent value of $D_{\mathrm{m}}^{\mathrm{e}}$, but also make it possible to accurately evaluate the standard deviation (uncertainty) by the method of constructing confidence intervals for linear regression coefficients, in the case of large observations. At present, however, we are limited by the fact that only two sets of experimental results with $\Delta \psi=2$ or $4 \mathrm{~V}$ are available for each of the tracers. As a result, we can only estimate one value of $D_{\mathrm{m}}^{\mathrm{e}}$ from this method while the mean and the standard deviation of $D_{\mathrm{m}}^{\mathrm{e}}$, as summarized latter in Table 8 , can only be evaluated from the available results given in Table 2 or Table 3 by use of the definitions. 
Table 3: Evaluation of the breakthrough curves obtained with $\mathrm{Na}_{2} \mathrm{SeO}_{3}$ as the tracer, using the ideal plug-flow model.

\begin{tabular}{|c|c|c|c|c|c|c|}
\hline$\Delta \psi(\mathrm{V})$ & $t_{\mathrm{B}}(\mathrm{hr})$ & $\kappa\left(\mu \mathrm{M} \mathrm{hr}^{-1}\right)$ & $D_{\mathrm{m}}^{\mathrm{e}}\left(\mathrm{m}^{2} \mathrm{~s}^{-1}\right)$ & $F_{\mathrm{f}}(-)$ & $\left.\tau_{\mathrm{A}}\right|_{R=1}(\mathrm{hr})$ & $R(-)$ \\
\hline 2.0 & 28.8 & 0.72 & $1.11 \times 10^{-14}$ & $1.11 \times 10^{-5}$ & 140.8 & 1.0 \\
\hline 4.0 & 22.4 & 4.21 & $3.26 \times 10^{-14}$ & $3.26 \times 10^{-5}$ & 23.9 & 1.0 \\
\hline \multicolumn{3}{|c|}{ Linear regression results } & $2.54 \times 10^{-14}$ & $2.54 \times 10^{-5}$ & & \\
\hline
\end{tabular}

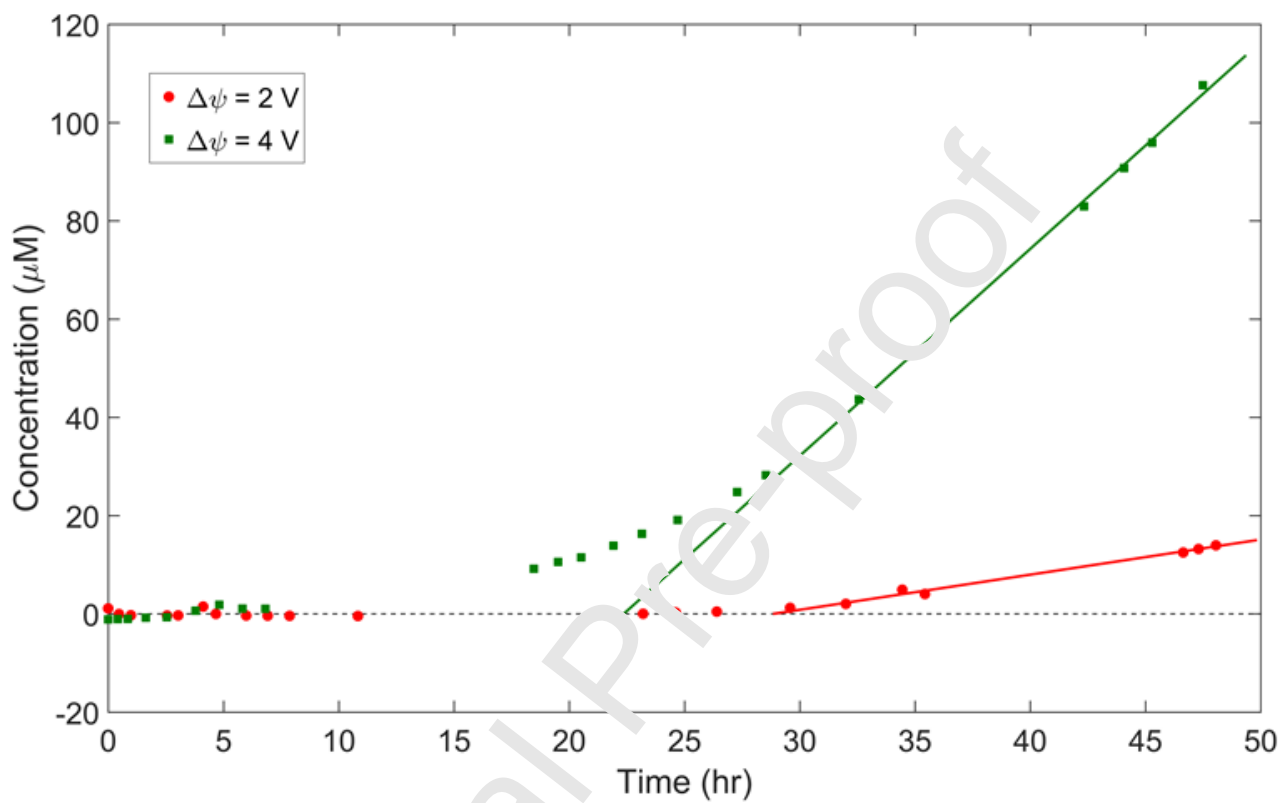

Fig. 3: The breakthrough curve of selenit,$w^{i}$ th wl applied voltage of $2 \mathrm{~V}$ or $4 \mathrm{~V}$ over the rock sample. Markers show the experimental data and the line giver a 'inear regression of the late-time data.

Likewise, the geometric formation factor $F_{\mathrm{f}}$ can also be determined from the slope of linear regression line of ${ }^{\mathrm{e}}, D_{\mathrm{m}}$ of a series of experiments, as suggested by Eq. (21). The results are also tabula ${ }^{\circ} \eta \mathrm{T}$; ble 2 and Table 3 , respectively, with $D_{\mathrm{m}}=2.04 \times 10^{-9} \mathrm{~m}^{2} \mathrm{~s}^{-1}$ for I(Atkins and De Paula, 分'y) and $D_{\mathrm{m}}=1.0 \times 10^{-9} \mathrm{~m}^{2} \mathrm{~s}^{-1}$ for $\mathrm{SeO}_{3}{ }^{2-}$ (Vlaev and Genieva, 2004), which is considered tc ${ }^{2}$ the main speciation of selenite under the performed experimental conditions.

To estimate the retardation factor $R$ of the tracers, one can also use Eq. (22) directly with $v_{\mathrm{c}}^{\mathrm{e}}$ evaluated from Eq. (19). However, it would be wise to first check if the inequality of Eq. (23) holds. Only under the condition of $t_{\mathrm{B}}>\left.\tau_{\mathrm{A}}\right|_{R=1}$, could $R$ be greater than unity. For this reason, we also tabulated in Table 2 and Table 3 the estimated value of $\left.\tau_{\mathrm{A}}\right|_{R=1}$ for each of the experiments assuming $\varepsilon_{\mathrm{TS}}=\varepsilon$, the total porosity of the rock sample of 0.007 . The results suggested that $t_{\mathrm{B}}<\left.\tau_{\mathrm{A}}\right|_{R=1}$ always holds for both iodide and selenite, and therefore they are effectively non-sorbing, leading to $R=1$. 


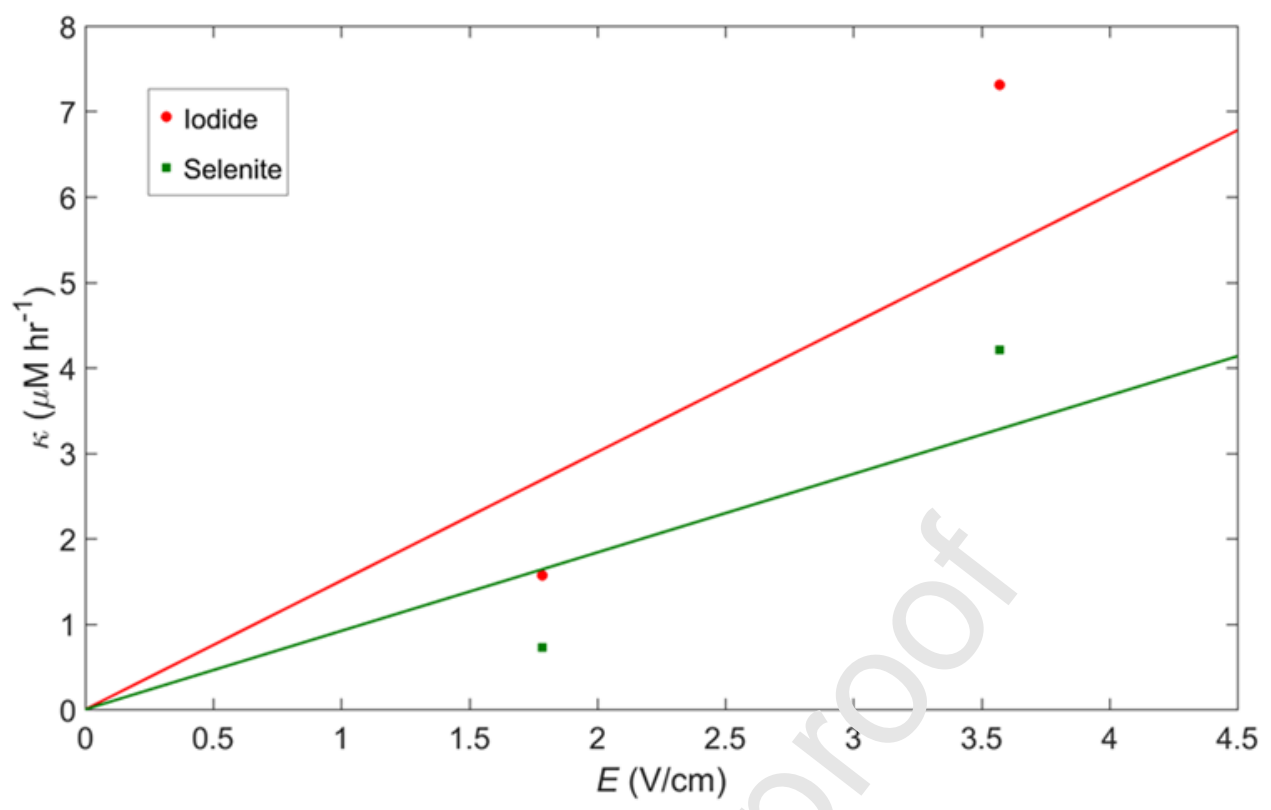

Fig. 4: The $\kappa$ value evaluated from the linear regression of the 'ate "ime breakthrough curve as a function of the applied electric field for both iodide and selenite, together w' .1 'he linear regression lines.

\subsection{Application of the advection-dispersion, model}

The inherent assumptions and simpli is atıns behind the ideal plug-flow model implies that it should better be used to give a quick $v$. rough estimate of $v_{\mathrm{c}}^{\mathrm{e}}, D_{\mathrm{m}}^{\mathrm{e}}, F_{\mathrm{f}}$, and $R$ etc. The results may, however, be valuable in efining the lower and upper bounds of the corresponding parameters for an accurate de rmı ration of the retardation properties of the intact rock by

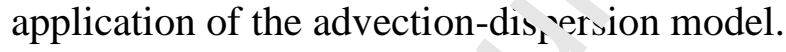

As discussed in $\mathrm{S}$ «ctı $\mathrm{n} 2$, the full solution of the advection-dispersion model in Laplace domain is given in Eq. '1 1 , . Although it looks intricate and tedious, a numerical algorithm of inverse Laplace transform (De Hoog et al., 1982) can easily be applied to give,

$c_{\mathrm{R}}=f\left(v_{\mathrm{c}}^{\mathrm{e}}, D^{\mathrm{e}}, \varepsilon_{\mathrm{TS}} R, c_{0}, t\right)$

This expression indicates that the evolution of the tracer concentration in the recipient chamber would depend only on $v_{\mathrm{c}}^{\mathrm{e}}, D^{\mathrm{e}}$, and $\varepsilon_{\mathrm{TS}} R$. As a result, these parameters can simultaneously be evaluated by fitting the numerical solution of $c_{\mathrm{R}}$ to the measured data of the breakthrough curves using e.g. a nonlinear least squares algorithm, supplemented with suitable lower and upper bounds. The computational expense is, therefore, increased a bit more than application of the ideal plug-flow model, but not much.

Since the advection-dispersion model well accounts for the most important mechanisms governing ion transport in the electromigration experiment, it would work in general cases where electroosmosis and dispersion may also play significant roles. When electroosmosis has been 
deemed to have a negligible contribution to convection, however, the dispersion coefficient $D^{\mathrm{e}}$ in Eq. (14) simplifies to,

$$
D^{\mathrm{e}}=D_{\mathrm{m}}^{\mathrm{e}}\left(1+\alpha \frac{z e E}{k_{\mathrm{B}} T}\right)
$$

This result suggests that, under the condition of $\mu_{\mathrm{eo}}^{\mathrm{e}}=0$, one may also identify $D_{\mathrm{m}}^{\mathrm{e}}$ and $\alpha$, instead of $v_{\mathrm{c}}^{\mathrm{e}}$ and $D^{\mathrm{e}}$, directly from the curve-fitting of the numerical solution of $c_{\mathrm{R}}$ to the breakthrough curves. As it is the case in our experiments (Li et al., 2019), we have applied this approach for analysis of the experimental data obtained for both iodide and selenite tracers. The results are summarized in Table 4 and Table 5 (the retardation factor $R$ are evaluated on the assumption of $\varepsilon_{\mathrm{TS}}=\varepsilon$ ), whereas the measured and the curve- itted breakthrough curves are given in Fig. 5 and Fig. 6, respectively.

Table 4: Evaluation of the breakthrough curves obtained with $\mathrm{NaI}$ as $+\ldots$ l.... $\mathrm{r}$, using the advection-dispersion model.

\begin{tabular}{ccccccc}
\hline$\Delta \psi(\mathrm{V})$ & $D^{\mathrm{e}}\left(\mathrm{m}^{2} \mathrm{~s}^{-1}\right)$ & $\varepsilon_{\mathrm{TS}} R(-)$ & $D_{\mathrm{m}}^{\mathrm{e}}\left(\mathrm{m}^{2} \mathrm{~s}^{-1}\right)$ & & $F_{\mathrm{f}}(-)$ & $R(-)$ \\
\hline 2.0 & $3.66 \times 10^{-13}$ & 0.007 & $1.09 \times 10^{-1}$ & & $5.34 \times 10^{-5}$ & 1.0 \\
4.0 & $6.95 \times 10^{-13}$ & 0.007 & $\left.1.2^{1} \sim^{1}\right)^{-13}$ & & $5.96 \times 10^{-5}$ & 1.0 \\
& Linear regression results & $1.1 \mathrm{~L}^{-5} \mathrm{r}^{13}$ & & $5.61 \times 10^{-5}$ & \\
\hline
\end{tabular}



Fig. 5: The breakthrough curve of iodide with an applied voltage of $2 \mathrm{~V}$ or $4 \mathrm{~V}$ over the rock sample. Markers show the experimental data and the line gives the curve-fitted results from the advection-dispersion model.

Note that we also include in Table 4 and Table 5 the estimated $D_{\mathrm{m}}^{\mathrm{e}}$ from the slope of the linear relationship between $D^{\mathrm{e}}$ and $E$, as indicated by Eq. (25), with $D^{\mathrm{e}}$ evaluated for each of the experiments under different applied voltages. As we discussed earlier, this approach would be very useful in determining the uncertainties associated with the data analysis in the case of large observations. At present, however, only two sets of experimental results are available for each of the tracers, and thereby making the linear regression analysis less powerful. 
The estimation of $R$ requires, remarkably, the value of $\varepsilon_{\text {TS }}$ to be known in advance because only $\varepsilon_{\mathrm{TS}} R$ can directly be evaluated from the data-fitting process. A useful approximation of $\varepsilon_{\mathrm{TS}}=\varepsilon$ would, then, have to be introduced in order to give $R$ a value unless $\varepsilon_{\mathrm{TS}}$ can be determined separately. This is also the case when the ideal plug-flow model was applied, as suggested by Eq. (22).

Having discussed these points, we should now emphasize that it is the use of all the available data of the experiments that has made the results of advection-dispersion model agree nicely with the measured breakthrough curves, as seen in Fig. 5 and Fig. 6, respectively. This indicates essentially that dispersion does play a non-negligible part in ionic transport through the rock sample, especially for selenite ions. As a consequence, one may also conclude that application of the ideal plug-flow model for parameter identificrtion can be really problematic because it ignores the effect of dispersion and uses only a sin ?ll portion of the late-time experimental results. This is, actually, in line with the observatir $n t$ t the regression lines of the ideal plug-flow model deviate in most cases from the mass..'d data at the time around breakthrough, as seen obviously in Fig. 3 .

Table 5: Evaluation of the breakthrough curves obtained with $\mathrm{Na}_{2}{ }^{\mathrm{r}}, \mathrm{el}$. as the tracer, using the advection-dispersion model.

\begin{tabular}{cccccc}
\hline$\Delta \psi(\mathrm{V})$ & $D^{\mathrm{e}}\left(\mathrm{m}^{2} \mathrm{~s}^{-1}\right)$ & $\varepsilon_{\mathrm{TS}} R(-)$ & $\left.D_{\mathrm{m}}^{\mathrm{e}} \mathrm{m}^{-} \mathrm{s}^{-1}\right)$ & $F_{\mathrm{f}}(-)$ & $R(-)$ \\
\hline 2.0 & $3.23 \times 10^{-13}$ & 0.007 & $87 \times \mathrm{N}^{-14}$ & $2.87 \times 10^{-5}$ & 1.0 \\
4.0 & $5.64 \times 10^{-13}$ & 0.007 & $3.14 \times 10^{-14}$ & $3.14 \times 10^{-5}$ & 1.0 \\
& \multicolumn{2}{c}{ Linear regression results } & $4.48 \times 10^{-14}$ & $4.48 \times 10^{-5}$ & \\
\hline
\end{tabular}



Fig. 6: The breakthrough curve of selenite with an applied voltage of $2 \mathrm{~V}$ or $4 \mathrm{~V}$ over the rock sample. Markers show the experimental data and the line gives the curve-fitted results from the advection-dispersion model. 


\subsection{Application of the reactive transport model}

As discussed in Section 2, the advection-dispersion model is developed without accounting for any speciation of the aqueous solution and ionic equilibrium as if the electrolyte does not exist. Although this is the common practice in the models proposed for performance assessment of deep geological repositories for spent nuclear fuel (Dershowitz et al., 1998; Gylling et al., 1999; Long et al., 1982; Marsic et al., 2001), the neglect of aqueous chemistry may influence the results of parameter identification to some extent. To examine how severe the deviations could be, a reactive transport model tailored for the electromigration cell shown in Fig. 1 should be applied. This would require us to reformulate the advection-dispersion model by replacing $c$ as $c_{\mathrm{i}}$, the concentration of the $i$ th species, in the governing equations as well as in the initial and boundary conditions, in addition to include mass-action equations, mass and charge balance equations, etc. as the geochemical model of PHREEQC (Parkhursı . nd Appelo, 2000) does. The implementation of such a reactive transport model is, however, tot . traightforward, especially in the cases considering individual diffusion coefficients for the ${ }^{-1}$ ute species. To address this problem in a simple means, one may interact with IPhreeq mo dules (Charlton and Parkhurst, 2011) that allows retrieving all of the simulation and da q-storage capabilities of PHREEQC through a limited set of methods. The use of e.g. the IPh eeqc COM module with the Python scripting language in a Windows environment (Charlto. and Parkhurst, 2011) would facilitate specific treatment of the boundary conditions a $a^{2}$ calculation of the reactive transport in a stepwise, coupled manner. At present, however, th\% w rk has not been fully completed yet.

Nevertheless, we note that in the $\mathrm{c}$ ises where electroosmosis has a marginal contribution to convection, as shown in our experiments, the implementation of the reactive transport model may become trivial because the availa ' $\mathrm{e}$ PHREEQC module for electromigration in aqueous solution can be utilized. As detailed $b$, inpelo (2017), this module is capable of simulating ionic transport in electromigration cells, hil . in ited in that it accounts only for molecular diffusion and electromigration. The effective ${ }^{*}$ ass flux of an ionic species is given by the Nernst-Planck equation:

$$
N_{\mathrm{i}}^{\mathrm{e}}=-D_{\mathrm{m}, \mathrm{i}}^{\mathrm{e}}\left(\frac{\partial c_{\mathrm{i}}}{\partial x}+\frac{z_{\mathrm{i}} e c_{\mathrm{i}}}{k_{\mathrm{B}} T} \frac{\partial \psi}{\partial_{.}} \cdot\right. \text {, }
$$

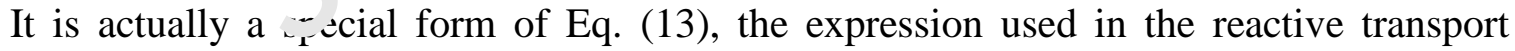
model we proposed, which is more general in the sense that the effects of electroosmosis and dispersion on ionic transport are also considered. This means that the Nernst-Planck equation would result only under the condition where $\mu_{\mathrm{eo}}^{\mathrm{e}}$ and $\alpha$ are both zero. In our experiments $\alpha=0$ might not hold, but still Eq. (13) can be simplified to give

$$
N_{\mathrm{i}}^{\mathrm{e}}=-D_{\mathrm{i}}^{\mathrm{e}}\left(\frac{\partial c_{\mathrm{i}}}{\partial x}+\frac{z_{\mathrm{i}} e c_{\mathrm{i}}}{k_{\mathrm{B}} T} \frac{D_{\mathrm{m}, \mathrm{i}}^{\mathrm{e}}}{D_{\mathrm{i}}^{\mathrm{e}}} \frac{\partial \psi}{\partial x}\right)
$$

The difference between this expression and the Nernst-Planck equation signifies that the PHREEQC module of electromigration (Appelo, 2017) is not directly applicable to our case because the ratio of $D_{\mathrm{m}, \mathrm{i}}^{\mathrm{e}} / D_{\mathrm{i}}^{\mathrm{e}}$ has a weak dependence on both $z_{\mathrm{i}}$ and the potential gradient, as can be justified from Eq. (14). However, it is expected that the electroneutrality condition would be 
more dominant than the ratio of $D_{\mathrm{m}, \mathrm{i}}^{\mathrm{e}} / D_{\mathrm{i}}^{\mathrm{e}}$ in determining the local mass flux. As a result, we may simply assume that the ratio of $D_{\mathrm{m}, \mathrm{i}}^{\mathrm{e}}$ over $D_{\mathrm{i}}^{\mathrm{e}}$ is a constant, independent of ionic species, with the aim of aiding for examination of the advection-dispersion model in data analysis. This allows, then, Eq. (27) to be rewritten in the same form as Eq. (26), i.e.,

$$
N_{\mathrm{i}}^{\mathrm{e}}=-D_{\mathrm{i}}^{\mathrm{e}}\left(\frac{\partial c_{\mathrm{i}}}{\partial x}+\frac{z_{\mathrm{i}} e c_{\mathrm{i}}}{k_{\mathrm{B}} T} \frac{\partial \psi^{\prime}}{\partial x}\right)
$$

with,

$$
\psi^{\prime}=\left(\frac{D_{\mathrm{m}, \mathrm{i}}^{\mathrm{e}}}{D_{\mathrm{i}}^{\mathrm{e}}}\right) \psi
$$

The introduction of the modified electric potential $\%$, istead of $\psi$, now makes it possible to use the PHREEQC module of electromigration Aps elo, 2017) for interpretation of our experimental results. The only price to pay is the cor 'ction of the applied voltage over the rock sample, $\Delta \psi$, by a species-independent, scaling fact $\operatorname{ro~}^{\mathrm{c}} \nu_{\mathrm{m}, \mathrm{i}}^{\mathrm{e}} / D_{\mathrm{i}}^{\mathrm{e}}$.

When applied practically for parameter identification, the PHREEQC module should be embedded into e.g. a Python script that facilitate ne use of IPhreeqc (Charlton and Parkhurst, 2011) and the implementation of the nonlinear ' ast squares algorithm. Using this approach, the breakthrough curves obtained in the expe im nts for both iodide and selenite tracers were also curve-fitted under the condition of $\mathrm{pH}=8.5$. ${ }^{\top} \mathrm{o}$ simplify the fitting procedure, however, we take the scaling factor of $D_{\mathrm{m}, \mathrm{i}}^{\mathrm{e}} / D_{\mathrm{i}}^{\mathrm{e}}$ as an unkı 'wn parameter to identify and do not consider individual diffusion coefficients for the solute s'er : as. The methodology of data analysis follows, then, the same steps as that described in Se^tic $\ 3.2$ for application of the advection-dispersion model. The results are summarized in Tai ${ }^{1} \mathrm{e} 6$ und Table 7, whereas the experimental data and the curvefitted breakthrough curves are g. 'en in Fig. 7 and Fig. 8, respectively.

It is seen that the estit. at $\mathrm{d}$ values of $D_{\mathrm{m}}^{\mathrm{e}}, F_{\mathrm{f}}$, and $R$ from the simplified, reactive transport model differs a bit from t lose obtained by the advection-dispersion model, but not much, in each of the cases studied. Co. "espondingly, the breakthrough curves calculated from both models are shown to coincide almest intirely for the same experiment. These findings suggest that the effect of aqueous chemistry is actually unimportant compared to electromigration and dispersion in governing ionic transport in the electromigration experiments. As a result, application of the advection-dispersion model for data analysis suffices to give reliable results.

Table 6: Evaluation of the breakthrough curves obtained with $\mathrm{NaI}$ as the tracer, using the reactive transport model.

\begin{tabular}{cccccc}
\hline$\Delta \psi(\mathrm{V})$ & $D^{\mathrm{e}}\left(\mathrm{m}^{2} \mathrm{~s}^{-1}\right)$ & $\varepsilon_{\mathrm{TS}} R(-)$ & $D_{\mathrm{m}}^{\mathrm{e}}\left(\mathrm{m}^{2} \mathrm{~s}^{-1}\right)$ & $F_{\mathrm{f}}(-)$ & $R(-)$ \\
\hline 2.0 & $3.83 \times 10^{-13}$ & 0.007 & $1.15 \times 10^{-13}$ & $5.62 \times 10^{-5}$ & 1.0 \\
4.0 & $7.83 \times 10^{-13}$ & 0.007 & $1.36 \times 10^{-13}$ & $6.67 \times 10^{-5}$ & 1.0 \\
& \multicolumn{2}{c}{ Linear regression results } & $1.24 \times 10^{-13}$ & $6.06 \times 10^{-5}$ & \\
\hline
\end{tabular}




\section{Journal Pre-proof}

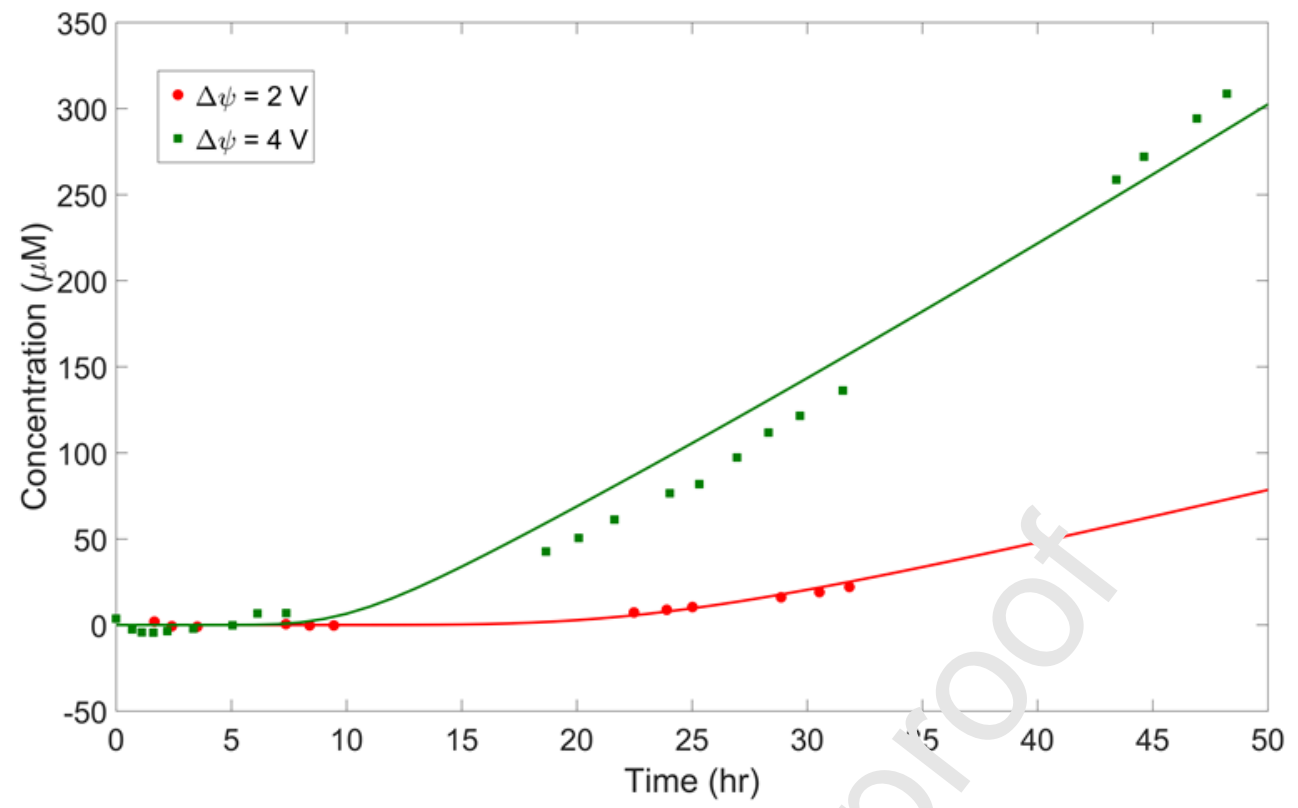

Fig. 7: The breakthrough curve of iodide with an applied voltage of ${ }^{\mathrm{V}}$ or $4 \mathrm{~V}$ over the rock sample. Markers show the experimental data and the line gives the curve-fitted resv' $\mathrm{is}$. om the reactive transport model.

Table 7: Evaluation of the breakthrough curves ob $^{+-\cdot}$ neu with $\mathrm{Na}_{2} \mathrm{SeO}_{3}$ as the tracer, using the reactive transport model.

\begin{tabular}{cccccc}
\hline$\Delta \psi(\mathrm{V})$ & $D^{\mathrm{e}}\left(\mathrm{m}^{2} \mathrm{~s}^{-1}\right)$ & $\left.\varepsilon_{\mathrm{TS}} K_{\mathrm{i}}^{\prime}\right)$ & $\nu_{\mathrm{m}}^{\mathrm{e}}\left(\mathrm{m}^{2} \mathrm{~s}^{-1}\right)$ & $F_{\mathrm{f}}(-)$ & $R(-)$ \\
\hline 2.0 & $1.73 \times 10^{-13}$ & $0 \mathrm{~s}^{7}$ & $3.83 \times 10^{-14}$ & $3.83 \times 10^{-5}$ & 1.0 \\
4.0 & $3.76 \times 10^{-13}$ & 0.017 & $4.05 \times 10^{-14}$ & $4.05 \times 10^{-5}$ & 1.0 \\
& Linear regression, sults & $3.37 \times 10^{-14}$ & $3.37 \times 10^{-5}$ & \\
\hline
\end{tabular}




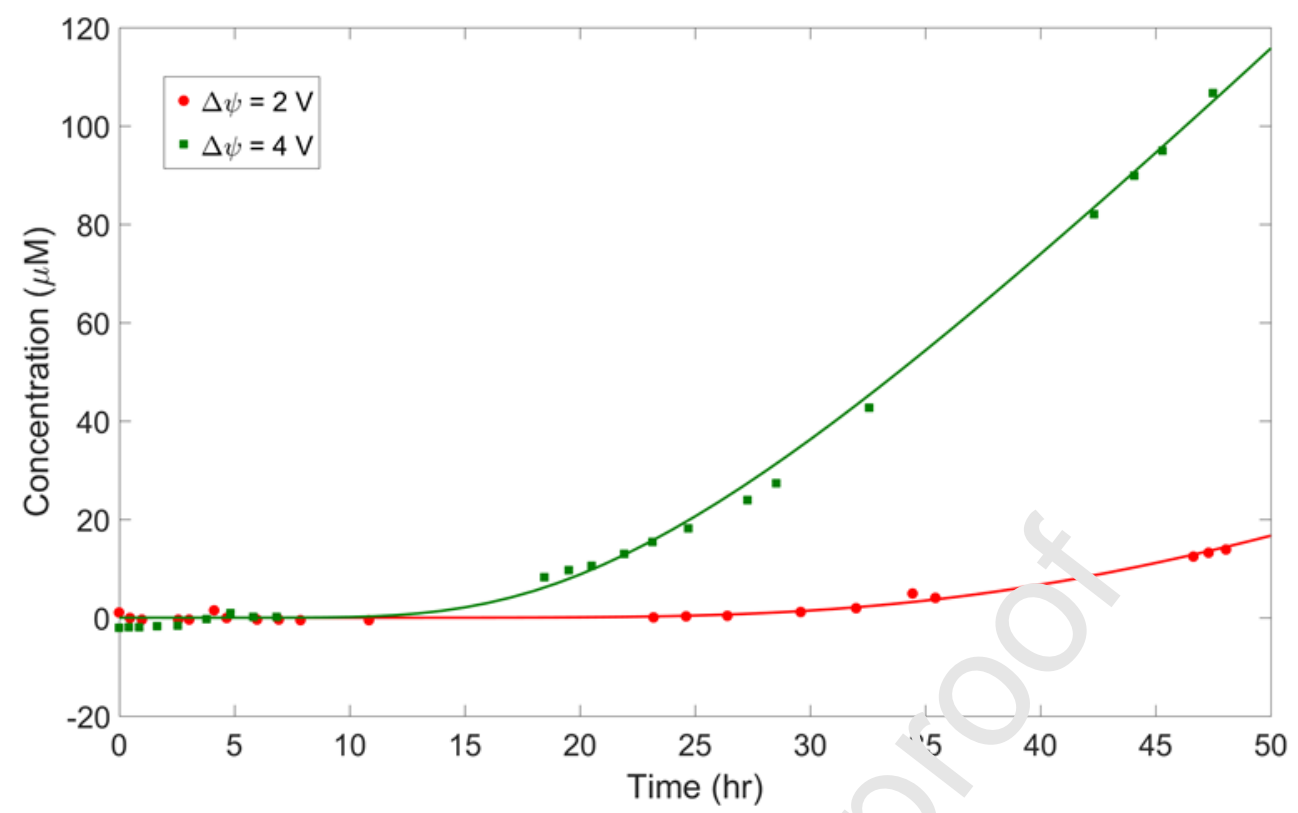

Fig. 8: The breakthrough curve of selenite with an applied voltag $f$ of $2 \mathrm{~V}$ or $4 \mathrm{~V}$ over the rock sample. Markers show the experimental data and the line gives the curve-fitted resu is om the reactive transport model.

\section{Discussion and conclusions}

To facilitate data analysis of the resi is of electromigration experiments with intact rock cores, an advection-dispersion model was (er eloped in the study that accounts for not only the dominant effect of electromigrati $n$ but also the contributions of electroosmosis and dispersion on ionic transport. It reduces tc the commonly used, ideal plug-flow model (André et al., 2009; Löfgren and Neretnieks, 2006, wnen dealing with a special case where only electromigration takes effect, and becomes the $r$ active transport model when extension to a multi-component system is made where th ef ect of aqueous chemistry is also considered. As a result, one may expect that the advectio:-aspersion model would stand somewhere in the middle of the other two models in both maplexity of computer implementations and flexibility of practical applications, as well as in veracity and reliability of parameter identifications. To show this is indeed the case, application of the models was particularly made to the cases we experimentally investigated by the updated electromigration device ( $\mathrm{Li}$ et al., 2019). The results are summarized in Table 8 for both iodide and selenite ions, where the mean and the standard deviation of $D_{\mathrm{m}}^{\mathrm{e}}$ and $F_{\mathrm{f}}$ are evaluated from those given in Table 2 to Table 7 by the definitions. 
Table 8: Summary of the results obtained from analysis of the breakthrough curves for both iodide and selenite tracers.

\begin{tabular}{ccccc}
\hline & \multicolumn{2}{c}{ Iodide } & \multicolumn{2}{c}{ Selenite } \\
\hline Model applied & $D_{\mathrm{m}}^{\mathrm{e}}\left(10^{-14} \mathrm{~m}^{2} \mathrm{~s}^{-1}\right)$ & $F_{\mathrm{f}}\left(10^{-5}\right)$ & $D_{\mathrm{m}}^{\mathrm{e}}\left(10^{-14} \mathrm{~m}^{2} \mathrm{~s}^{-1}\right)$ & $F_{\mathrm{f}}\left(10^{-5}\right)$ \\
\hline Ideal plug-flow model & $8.33 \pm 3.25$ & $4.06 \pm 1.59$ & $2.30 \pm 0.89$ & $2.30 \pm 0.89$ \\
Advection-dispersion model & $11.5 \pm 0.60$ & $5.61 \pm 0.29$ & $3.50 \pm 0.86$ & $3.50 \pm 0.86$ \\
Reactive transport model & $12.5 \pm 1.05$ & $6.11 \pm 0.51$ & $3.75 \pm 0.35$ & $3.75 \pm 0.35$ \\
\hline Data reported in literature & $1.0 \sim 46.0$ & $1.0 \sim 20.0$ & $1.0 \sim 10.0$ & $1.0 \sim 20.0$ \\
\hline
\end{tabular}

It is seen that the effective diffusivities of iodide and selenite estimated from our experimental results are, all together, in good agreement with data reported in literature (André et al., 2009; Ohlsson and Neretnieks, 1997; Vecernik et al., 2013) irr pective of which model is applied. Likewise, the formation factors evaluated from differe it $c_{i}$ ses also fall fairly well into the range of data derived from other experiments (Löfgrer a. a iveretnieks, 2005; Thunehed, 2005). However, the results of the ideal plug-flow model s'ic $v$ a larger difference than the other two models in both mean values and uncertainties (i.e se standard deviations), due to the neglect of the dispersion mechanism and also the diff: ult. in selecting suitable data points for regression analysis. By comparison, the advection-dis rsion model gives nearly the same estimates of parameters as the reactive transport $r$ or 2 , with only minor differences in the mean values and uncertainties. This suggests that one $n \cdot \cdot v$ gnore the influence of aqueous chemistry

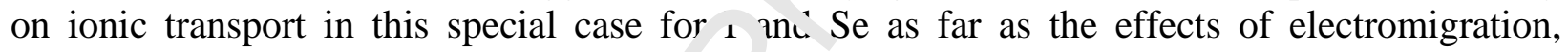
electroosmosis and dispersion are properly ta'.en into account. As a consequence, the advectiondispersion model should be applied in the fir ${ }^{+}$place to interpret the results of electromigration experiments, due to its ease in implement tion and sufficient accuracy in data analysis.

In addition, we noticed fr. $n$ ' $n$ ole 2 to Table 7 that the retardation factor $R$ for the transport of iodide and selenite arc always unity even in the worst case where the ideal plug-flow model was applied for data $a_{1}$. alysis. It seems, therefore, that both iodide and selenite are effectively non-sorbing in the wrk core investigated in this work. For iodide, this is expected (André et al., 2009; Ohls $\leadsto \eta$ d Neretnieks, 1997), while for selenite the results from batch experiments with crus hec roc ss suggested that it is a weakly sorbing species, with $K_{\mathrm{d}}$ values on the order of $2.95 \times 10^{-4} \mathrm{~m}^{3} \mathrm{~kg}$ for Forsmark and Laxemar granites (Crawford, 2010) and 2.0 $\times 10^{-3}$ $\mathrm{m}^{3} / \mathrm{kg}$ for Grimsel grai=diorite (Li et al., 2018). We found, however, that the assumption of selenite as a sorbing species always made the curvature of the simulated breakthrough curves to deviate clearly from that obtained in the experiments, especially at the moments around the breakthrough time, when the advection-dispersion model or the reactive transport model was used. It is, then, believed that crushed rock samples have somewhat different sorption capabilities than original intact rocks due to a significant increase in the specific surface area of the rock samples and an access to otherwise isolated pores or minerals. The reason why selenite migrate relative slowly in comparison with iodide is attributed mainly to its smaller effective diffusivity (see the results in Table 8) as a result of the larger size and unsymmetrical dimensions of selenite ions, as well as the existence of hydrogen bond between selenite ions and water molecules (Li et al., 2019). Since the size and geometry of hydrated ions are also decisive in determining the transport porosity, tortuosity, and constrictivity for their transport through the micropores of intact rock, it is not surprising to see in Table 8 that the formation factor $F_{\mathrm{f}}$, as 
defined in Eq. (A9), is species-dependent. The value obtained from analysis of the breakthrough curves of iodide is a bit larger than that evaluated from the experimental results of selenite, no matter which model is used for parameter identification.

All these findings also substantiate from another side that the updated electromigration device can be used, with great confidence, to provide experimental results of high quality for diffusion and sorption studies of radionuclides in intact rocks ( $\mathrm{Li}$ et al., 2019). The reason is obvious, because no model can obtain right interpretations from wrong or bad data of experiments. Likewise, right interpretations can neither be obtained from a bad model even if the experimental results are good enough. Thus, the choice of the models is crucial. The advectiondispersion model is competent for the parameter identification by interpreting experimental results of electromigration. It gives nearly the same quality of data analysis as the complex, reactive transport model at the price of a little more computational Jemanding than the classical, ideal plug-flow model. In addition, it has an advantage in th if lie estimated parameters can directly be used in the models developed for safety assessment of deep geological repositories for spent nuclear fuel (Dershowitz et al., 1998; Gylling et al 19 19; Long et al., 1982; Marsic et al., 2001), because they also commonly ignore the ef ' ct of aqueous chemistry on solute transport.

Detailed studies of I, Se, Cs, and Sr, will bu periormed with e.g. 5 or more applied voltages over the different type of rock samples i 1 s stromigration experiments by the updated device in the near future ( $\mathrm{Li}$ et al., 2019). This ill make the method of constructing confidence intervals for linear regression coefficients $\mathrm{Ma}$ is et al., 1999) favorable for parameter evaluations by application of the advection-dispersio. model, and thereby decrease the uncertainties associated with the diffusion and sorptı? properties of the nuclides.

\section{Nomenclature}

A: Cross-sectional area of thi roc sample, $\left[\mathrm{L}^{2}\right]$

$D$ : Dispersion coefficı $\left.n t,{ }^{[\mathrm{I}}{ }^{2} \mathrm{r}^{-1}\right]$

$D^{\mathrm{e}}$ : Effective dispersion woefficient, $\left[\mathrm{L}^{2} \mathrm{~T}^{-1}\right]$

$D_{\mathrm{m}}:$ Molecular diffusion coefficient in unconfined pore water, $\left[\mathrm{L}^{2} \mathrm{~T}^{-1}\right]$

$D_{\mathrm{m}}^{\mathrm{e}}$ : Effective diffusion coefficient, $\left[\mathrm{L}^{2} \mathrm{~T}^{-1}\right]$

$E$ : Electric field over the rock sample, $\left[\mathrm{VL}^{-1}\right]$

$F_{\mathrm{f}}$ : The formation factor, [-]

$J_{\mathrm{D}}$ : Dispersive mass transfer, $\left[\mathrm{MT}^{-1} \mathrm{~L}^{-2}\right]$

$K_{\mathrm{d}}$ : Distribution coefficient, $\left[\mathrm{L}^{3} \mathrm{M}^{-1}\right]$ 
$L$ : Length of the rock sample, [L]

$N^{\mathrm{e}}$ : Effective mass flux, $\left[\mathrm{MT}^{-1} \mathrm{~L}^{-2}\right]$

Pe: Péclet number, [- ]

$R$ : Retardation factor, [- ]

$S$ : Defined parameter, [-]

$T$ : Absolute temperature, $[\mathrm{K}]$

$V_{\mathrm{L}}$ : Volume of the source chamber, $\left[\mathrm{L}^{3}\right]$

$V_{\mathrm{R}}$ : Volume of the recipient chamber, $\left[\mathrm{L}^{3}\right]$

c: Species concentration, $\left[\mathrm{ML}^{-3}\right]$

$\bar{c}$ : Laplace transformed species concentration, $\left[\mathrm{M}^{7} \cdot \mathrm{L}^{-s^{7}}\right.$

$c_{\mathrm{L}}:$ Species concentration in the source cha $n \mathrm{~b} r \mathrm{r},\left[\mathrm{L}^{1} \mathrm{~L}^{-3}\right]$

$\bar{c}_{\mathrm{L}}$ : Laplace transformed source concer ${ }^{\star}$ ration, $\left.{ }_{\mathrm{L}} \mathrm{MTL}^{-3}\right]$

$c_{\mathrm{R}}$ : Species concentration in the recip er. 'hamber, $\left[\mathrm{ML}^{-3}\right]$

$\bar{c}_{\mathrm{R}}$ : Laplace transformed recipiert - nncentration, $\left[\mathrm{MTL}^{-3}\right]$

$e$ : Electron charge, [C]

$k_{\mathrm{B}}$ : Boltzmann constant, $\mathrm{CVI}^{-1}$ ]

$q$ : Tracer concentration in the solid, $\left[\mathrm{ML}^{-3}\right]$

$s:$ Laplace variable, $\left[\mathrm{T}^{-1}\right]$

$t$ : Time, $\left[\mathrm{T}^{-1}\right]$

$t_{\mathrm{B}}$ : Intercept of the regression line with the time coordinate, $[\mathrm{T}]$

$u(t)$ : The Heaviside step function, [-]

$v_{\mathrm{c}}$ : Convection velocity, $\left[\mathrm{LT}^{-1}\right]$

$v_{c}^{\mathrm{e}}$ : Effective convection velocity, [ $\mathrm{LT}^{-1}$ ] 
$v_{\mathrm{em}}:$ Drift or electromigration speed, $\left[\mathrm{LT}^{-1}\right]$

$v_{\mathrm{em}}^{\mathrm{e}}$ : Effective drift or electromigration speed, $\left[\mathrm{LT}^{-1}\right]$

$v_{\mathrm{eo}}$ : Electroosmotic velocity, $\left[\mathrm{LT}^{-1}\right]$

$v_{\mathrm{eo}}^{\mathrm{e}}:$ Effective electroosmotic velocity, $\left[\mathrm{LT}^{-1}\right]$

$x$ : Position in the direction of the concentration gradient, [L]

$z$ : Valence of the tracer ions, $[-]$

$\alpha$ : Dispersion length, [L]

$\beta_{\mathrm{L}}$ : Relaxation time of the source chamber, [T]

$\beta_{\mathrm{R}}$ : Relaxation time of the recipient chamber, [T]

$\delta$ : Constrictivity, $[-]$

$\varepsilon_{\mathrm{T}}$ : Porosity associated with the transport, [- ]

$\varepsilon_{\mathrm{TS}}$ : Porosity available for both transpc.+ and storage, [- ]

$\kappa$ : Slope of the regression line, $\left[\mathrm{MT}^{-} \mathrm{I}^{-}\right.$

$\mu$ : Ionic mobility, $\left[\mathrm{L}^{2} \mathrm{~V}^{-1} \mathrm{~T}^{-1}\right]$

$\mu_{\mathrm{eo}}$ : Electroosmotic mobilit: $\left[\mathrm{L}^{\urcorner} \mathrm{v}^{-1} \mathrm{~T}^{-1}\right]$

$\mu_{\mathrm{eo}}^{\mathrm{e}}$ : Effective electro $s \mathrm{~m}$ tic nobility, $\left[\mathrm{L}^{2} \mathrm{~V}^{-1} \mathrm{~T}^{-1}\right]$

$\rho$ : Dry bulk density of $\mathrm{n} \sim$ asured rock sample, $\left[\mathrm{ML}^{-3}\right]$

$\tau$ : Tortuosity, [- ]

$\tau_{\mathrm{A}}:$ Characteristic advection time, $[\mathrm{T}]$

$\left.\tau_{\mathrm{A}}\right|_{R=1}$ : The value of $\tau_{\mathrm{A}}$ in the case of $R=1,[\mathrm{~T}]$

$\psi$ : Electric potential, [V]

$\psi^{\prime}$ : Modified electric potential 


\section{Acknowledgement}

The authors gratefully acknowledge the encouragement and financial support of the Swedish Nuclear Fuel and Waste Management Company (SKB).

\section{Appendix A: The dominant mechanisms involved in electromigration experiments}

In the though-electromigration experiments, as illustrated in Fig. 1, cations and anions are forced to move through the water-saturated rock sample towards the electrode of opposite charge when subjected to an electrical field. The movement of ions will, then, be influenced by three important mechanisms: electromigration, electroosmosis, and dispersion, as detailed by Maes et al. (1999).

Electromigration indicates that electrical field forces $\mathrm{cr}_{\mu_{e}}{ }^{-e}$ species to migrate to the electrode of opposite charge. Under the influence of potential g ad' ant, the ions will move at a velocity called the drift speed, $v_{\mathrm{em}}$, which depends on the el sctr :al field and the ionic mobility, i.e.,

$v_{\mathrm{em}}=-\mu \frac{\partial \psi}{\partial x}$

where $\mu$ is the ionic mobility.

The ionic mobility can be related 4 molecular diffusion coefficient $D_{\mathrm{m}}$ by the law of Einstein (Atkins, 1984), which gives,

$D_{\mathrm{m}}=\frac{\mu k_{\mathrm{B}} T}{z e}$

Electroosmosis is the L 1/k flow of water towards the cathode. It can be explained by the presence of an electrical do hle iayer at the charged surface of the rock minerals (Maes et al., 1999): the negatively cha ge' pore walls of the rocks are compensated by the cations in the pore water (Revil, 1999; An ${ }^{1} r e$ at d., 2009). Under the influence of an electrical field, the mobile part of the cations in the elec ical double layer migrate to the cathode and by viscous drag a bulk flow of pore water occurs towards the cathode. The electroosmotic velocity, $v_{\mathrm{eo}}$, also varies linearly with the magnitude of the electrical field:

$$
v_{\mathrm{eo}}=-\mu_{\mathrm{eo}} \frac{\partial \psi}{\partial x}
$$

where $\mu_{\mathrm{eo}}$ is the electroosmotic mobility.

Dispersion is the spreading of mass from highly concentrated areas to less concentrated areas. As a mixing process, it is analogous to diffusion in that Fick's first law can still be used to describe the dispersive mass transfer, which assumes that the mass flux, $J_{\mathrm{D}}$, is proportional to the negative of the concentration gradient of the species, i.e., 


$$
J_{\mathrm{D}}=-D \frac{\partial c}{\partial x}
$$

where $D$ is the dispersion coefficient.

Dispersion can be differentiated from diffusion in that it is caused by non-ideal flow patterns (i.e. deviations from the plug flow) and the general relation between the dispersion coefficient and the molecular diffusion coefficient is commonly written as (Beauwens et al., 2005)

$$
D=D_{\mathrm{m}}+\alpha v_{\mathrm{c}}
$$

where $\alpha$ is the dispersion length, and $v_{\mathrm{c}}$ is the total convection vei ccity that causes dispersion, composed of both $v_{\mathrm{em}}$ and $v_{\mathrm{eo}}$ :

$$
v_{\mathrm{c}}=v_{\mathrm{em}}+v_{\mathrm{eo}}
$$

Under coupling action of electromigration, eler roo mosis, and dispersion, the mass flux of an ionic species can be written as

$$
N=c v_{\mathrm{c}}-D \frac{\partial c}{\partial x}
$$

Note that all the expressions given in ${ }^{\mathrm{q}} \mathrm{qs}$. (A1) to (A7) are valid only for the case of a bulk solution. When applied to desci he ionic transport in electromigration experiments, however, the effective counterparts ar , ommonly involved. Taking the effective convection velocity as an example, it is related $\sim \imath_{\imath}$ jy

$v_{\mathrm{c}}^{\mathrm{e}}=F_{\mathrm{f}} v_{\mathrm{c}}$

with the formation factor. ¿ f filıd as (Löfgren, 2004):

$$
F_{\mathrm{f}}=\varepsilon_{\mathrm{T}} \frac{\delta}{\tau^{2}}
$$

where $\varepsilon_{\mathrm{T}}$ is the porosity associated with the transport, $\delta$ is the constrictivity, considered to depend on the ratio of the diameter of the ions to the pore diameter, and $\tau$ is the tortuosity, defined as the ratio between the real distance of the transport path and the experimentally measured end to end distance.

Similar relation as Eq. (A8) also applies to other effective entities, such as the effective electroosmotic mobility, the effective electroosmotic velocity, the effective molecular diffusion coefficient, and the efficient dispersion coefficient, etc. 
Appendix B: The Laplace-transformed solution of the advection-dispersion model

By applying Laplace transform to both Eqs. (2) and (11), we find,

$$
s \bar{c}=-\frac{v_{\mathrm{c}}^{\mathrm{e}}}{\varepsilon_{\mathrm{TS}} R} \frac{\partial \bar{c}}{\partial x}+\frac{D^{\mathrm{e}}}{\varepsilon_{\mathrm{TS}} R} \frac{\partial^{2} \bar{c}}{\partial x^{2}}
$$

where $s$ is Laplace variable, and $\bar{c}$ is the Laplace transformation of $c$, defined as,

$$
\bar{c}(x, s)=\int_{0}^{\infty} \exp (-s t) c(x, t) \mathrm{d} t
$$

The general solution to Eq. (B1) is of the form,

$\bar{c}=C_{1} \exp \left(B_{+} x / L\right)+C_{2} \exp \left(B_{-} x / L\right)$

with

$B_{ \pm}=\frac{\mathrm{Pe}}{2} \pm S$

and

$$
S=\frac{\mathrm{Pe}}{2} \sqrt{1+\frac{4 \tau_{\mathrm{A}} s}{\mathrm{Pe}}}
$$

In writing the last two ex or sions, we have defined a Péclet number:

$$
\mathrm{Pe}=\frac{L v_{\mathrm{c}}^{\mathrm{e}}}{D^{\mathrm{e}}}
$$

and the characteristic adve stion time, $\tau_{\mathrm{A}}$, given by,

$$
\tau_{\mathrm{A}}=\frac{\varepsilon_{\mathrm{TS}} R L}{v_{\mathrm{c}}^{\mathrm{e}}}
$$

The constants in Eq. (B3) can be obtained by applying the boundary conditions of Eqs. (5) and (6), leading to,

$$
C_{1}=-\frac{\bar{c}_{\mathrm{L}} \exp (-S)-\bar{c}_{\mathrm{R}} \exp \left(-\frac{\mathrm{Pe}}{2}\right)}{2 \sinh (S)}
$$

and 
$C_{2}=\frac{\bar{c}_{\mathrm{L}} \exp (S)-\bar{c}_{\mathrm{R}} \exp \left(-\frac{\mathrm{Pe}}{2}\right)}{2 \sinh (S)}$

where $\bar{c}_{\mathrm{L}}$ is the Laplace transformation of $c_{\mathrm{L}}$.

by

It follows that the gradient of $\bar{c}$ at the interface $x=0$ and $x=L$ are given, respectively,

$\left.L \frac{\partial \bar{c}}{\partial x}\right|_{x=0}=C_{1} B_{+}+C_{2} B_{-}$

and

$\left.L \frac{\partial \bar{c}}{\partial x}\right|_{\mathrm{x}=\mathrm{L}}=C_{1} B_{+} \exp \left(B_{+}\right)+C_{2} B_{-} \exp \left(B_{-}\right)$

With this, we now proceed to apply the Lapla e $t$ ansform to Eqs. (7) and (9) for the chambers. Upon substitution of the effective mass flux $N^{t}$, ve get,

$$
s \bar{c}_{\mathrm{L}}-c_{0}=-\left.\frac{1}{\beta_{\mathrm{L}}}\left(\bar{c}-\frac{L}{\operatorname{Pe}} \frac{\partial \bar{c}}{\partial x}\right)\right|_{\mathrm{x}=0}
$$

and

$$
s \bar{c}_{\mathrm{R}}=\left.\frac{1}{\beta_{\mathrm{R}}}\left(-\bar{c}-\frac{L}{\mathrm{Pe}} \frac{\partial \bar{c}}{\partial x}\right)\right|_{\mathrm{x}=\mathrm{L}}
$$

where $\beta_{\mathrm{L}}$ and $\beta_{\mathrm{R}}$ are the relax tion time of the source and recipient chambers, respectively, defined as:

$\beta_{\mathrm{L}}=\frac{V_{\mathrm{L}}}{A v_{\mathrm{c}}^{\mathrm{e}}}$

and

$$
\beta_{\mathrm{R}}=\frac{V_{\mathrm{R}}}{A v_{\mathrm{c}}^{\mathrm{e}}}
$$

It follows that combination of the above four equations allows us to write

$\left(\frac{1}{\beta_{\mathrm{L}}}+s\right) \bar{c}_{\mathrm{L}}=\frac{1}{\operatorname{Pe} \beta_{\mathrm{L}}}\left(C_{1} B_{+}+C_{2} B_{-}\right)+c_{0}$

and 
$\left(\frac{1}{\beta_{\mathrm{R}}}-s\right) \bar{c}_{\mathrm{R}}=\frac{1}{\operatorname{Pe} \beta_{\mathrm{R}}}\left[C_{1} B_{+} \exp \left(B_{+}\right)+C_{2} B_{-} \exp \left(B_{-}\right)\right]$

With the use of Eq. (B8) and (B9) for $C_{1}$ and $C_{2}$, respectively, we find

$\left[\frac{\mathrm{Pe}}{2}+\mathrm{Pe} \beta_{\mathrm{L}} s+S \operatorname{coth}(S)\right] \bar{c}_{\mathrm{L}}=S \exp \left(-\frac{\mathrm{Pe}}{2}\right) \operatorname{csch}(S) \bar{c}_{\mathrm{R}}+\mathrm{Pe} \beta_{\mathrm{L}} c_{0}$

and

$\left[\frac{\mathrm{Pe}}{2}-\mathrm{Pe} \beta_{\mathrm{R}} s-S \operatorname{coth}(S)\right] \bar{c}_{\mathrm{R}}=-S \exp \left(\frac{\mathrm{Pe}}{2}\right) \operatorname{csch}(S) \bar{c}_{\mathrm{L}}$

The results are, therefore, given by

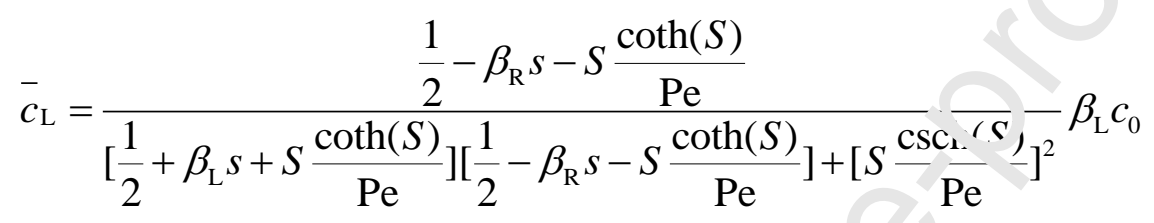

and

$\bar{c}_{\mathrm{R}}=-\frac{S \frac{\operatorname{csch}(S)}{\mathrm{Pe}}}{\left[\frac{1}{2}+\beta_{\mathrm{L}} s+S \frac{\operatorname{coth}(S)}{\mathrm{Pe}}\right]\left[\frac{1}{2}-\beta_{\mathrm{R}} s-\frac{\mathrm{Ohh}(S)}{\mathrm{Pe}}\right]+\left[S \frac{\operatorname{csch}(S)}{\mathrm{Pe}}\right]^{2}} \exp \left(\frac{\mathrm{Pe}}{2}\right) \beta_{\mathrm{L}} c_{0}$

This is the origin of Eq. 15$)$.

\section{Appendix C: The Lap: 'a :ansformed solution of the ideal plug-flow model}

In the limiting case as $\mathrm{Pe} \rightarrow \infty$ or equivalently $D^{\mathrm{e}} \rightarrow 0$, Eq. (B1) reduces to,

$$
\overline{s c}=-\frac{v_{\mathrm{c}}^{\mathrm{e}}}{\varepsilon_{\mathrm{TS}} R} \frac{\partial \bar{c}}{\partial x}
$$

When use is made of the boundary conditions, i.e. Eqs. (7) and (9), in the Laplace domain, we obtain

$\bar{c}=\bar{c}_{\mathrm{L}} \exp \left(-\frac{x}{L} \tau_{\mathrm{A}} s\right)$

Substitution of this result into Eqs. (B12) and (B13), respectively, it gives, 


$$
\bar{c}_{\mathrm{L}}=\frac{c_{0}}{s+\frac{1}{\beta_{\mathrm{L}}}}
$$

and

$\bar{c}_{\mathrm{R}}=\frac{c_{0}}{\beta_{\mathrm{R}}} \frac{1}{\left(s+\frac{1}{\beta_{\mathrm{L}}}\right) s} \exp \left(-\tau_{\mathrm{A}} s\right)$

This is the origin of Eq. (16). The inverse Laplace transform can readily be performed by making use of the identity (Abramowitz and Stegun, 1965):

$$
L^{-1}\left[\frac{1}{(s+a)(s+b)}\right]=\frac{\exp (-a t)-\exp (-b t)}{b-a}, a \neq b
$$

where $L^{-1}$ denotes the operator of the inverse Laplace $\mathrm{t}$ ans ${ }^{c}$ or m.

The result is given in Eq. (17).

\section{References}

Abramowitz, M., \& Stegun, I. A. (1965). I'tandbook of Mathematical Functions: With Formulas, Graphs, and Mathematical Tabl's Luver Publications. New York.

André, M., Malmström, M. E., \& 1 retnieks, I. (2009). Determination of sorption properties of intact rock samples: New mi thods based on electromigration. Journal of Contaminant Hydrology, 103(3), 71- 91. 1 tps://doi.org/https://doi.org/10.1016/j.jconhyd.2008.09.006

Appelo, C. A. J. (2017) i llu 2 transport solved with the Nernst-Planck equation for concrete pores with 'free' wa 'r and a double layer. Cement and Concrete Research, 101, 102-113. https://doi.org/10.i i6/J.CEMCONRES.2017.08.030

Atkins, P., \& De Paula, J. (2009). Elements of Physical Chemistry. Oxford University Press (5th ed.). New York.

Atkins, P. W. (1984). Elements of Physical Chemistry. Oxford University Press (5th ed.). New York.

Beauwens, T., De Cannière, P., Moors, H., Wang, L., \& Maes, N. (2005). Studying the migration behaviour of selenate in Boom Clay by electromigration. Engineering Geology (Vol. 77). https://doi.org/10.1016/j.enggeo.2004.07.019

Boyle, C. H., \& Meguid, S. A. (2015). Mechanical performance of integrally bonded copper coatings for the long term disposal of used nuclear fuel. Nuclear Engineering and Design, 
293, 403-412. https://doi.org/https://doi.org/10.1016/j.nucengdes.2015.08.011

Charlton, S. R., \& Parkhurst, D. L. (2011). Modules based on the geochemical model PHREEQC for use in scripting and programming languages. Computers \& Geosciences, 37(10), 16531663. https://doi.org/https://doi.org/10.1016/j.cageo.2011.02.005

Crawford, J. (2010). Bedrock Kd data and uncertainty assessment for application in SR-Site geosphere transport calculations (No. R-10-48). Swedish Nuclear Fuel and Waste Management Company (SKB), R-Report, R-10-48. Stockholm.

De Hoog, F., Knight, J., \& Stokes, A. (1982). An Improved Method for Numerical Inversion of Laplace Transforms. SIAM Journal on Scientific and Statistical Computing, 3(3), 357-366. https://doi.org/10.1137/0903022

Dershowitz, W., Lee, G., Geier, J., Foxford, T., LaPointe, P., \& Thor 1as, A. (1998). FracMan version 2.6: Interactive discrete feature data analysis, $g$ 'om 'tric, modeling, and exploration simulation - User documentation (No. Report 923-10 9). Solder Assoc. Inc. Seattle, Washington.

García-Gutiérrez, M., Cormenzana, J. L., Missana, T., 'Miı_ ‘arro, M., \& Martin, P.-L. (2006). Large-scale laboratory diffusion experiments in clay rocks. Physics and Chemistry of the Earth, Parts A/B/C (Vol. 31). https://doi.or:/1 ' 1 J16/j.pce.2006.04.004

Gylling, B., Moreno, L., \& Neretnieks, I. (; ar y). The Channel Network Model-A Tool for Transport Simulations in Fractured Mean. Ground Water (Vol. 37). https://doi.org/10.1111/j.1745-6584.: 999.tb01113.x

Heinemann, I., \& Frischat, G. H. (19), jodium transport mechanism in Na2O-2SiO2 glass determined by the chemla ex $x_{1}$ ariment. Physics and Chemistry of Glasses, 34(6), 255-260. Retrieved from https://wwh scopus.com/inward/record.uri?eid=2-s2.00027845328\&partnerID=4i \&md5=625f43a714e7ed7bf236bbd01d27c8ef

Ikonen, J., Voutilaine? N '., S iderlund, M., Jokelainen, L., Siitari-Kauppi, M., \& Martin, A. (2016). Sorption an' diffusion of selenium oxyanions in granitic rock. Journal of Contaminant Hydr $\urcorner$, gy, 192, 203-211. https://doi.org/https://doi.org/10.1016/j.jconhyd.2016.08.003

Li, X., Puhakka, E., Ikonen, J., Söderlund, M., Lindberg, A., Holgersson, S., ... Siitari-Kauppi, M. (2018). Sorption of Se species on mineral surfaces, part I: Batch sorption and multi-site modelling. Applied Geochemistry, 95, 147-157. https://doi.org/https://doi.org/10.1016/j.apgeochem.2018.05.024

Löfgren, M. (2004). Diffusive properties of granitic rock as measured by in-situ electrical methods. Doctoral dissertation, TRITA-KET R206. KTH Royal Institute of Technology, Stockholm.

Löfgren, M., \& Neretnieks, I. (2005). Oskarshamn site investigation: Formation factor logging in-situ by electrical methods in KLX03 and KLX04. Swedish Nuclear Fuel and Waste 
Management Company (SKB), P-report, P-05-105. Stockholm.

Löfgren, M., \& Neretnieks, I. (2006). Through-electromigration: A new method of investigating pore connectivity and obtaining formation factors. Journal of Contaminant Hydrology, 87(3), 237-252. https://doi.org/https://doi.org/10.1016/j.jconhyd.2006.05.006

Long, J. C. S., Remer, J. S., Wilson, C. R., \& Witherspoon, P. A. (1982). Porous media equivalents for networks of discontinuous fractures. Water Resources Research, 18(3), 645658. https://doi.org/10.1029/WR018i003p00645

Maes, N, Moors, H., Dierckx, A., De Cannière, P., \& Put, M. (1999). The assessment of electromigration as a new technique to study diffusion of radionuclides in clayey soils. Journal of Contaminant Hydrology, 36(3), 231-247. https://doi.org/https://doi.org/10.1016/S0169-7722(98)0014':

Maes, Norbert, Moors, H., Wang, L., Delècaut, G., De Canni sre, D., \& Put, M. (2002). The use of electromigration as a qualitative technique to study th? $m_{0}$. ation behaviour and speciation of uranium in the Boom Clay. Radiochimica Acta ( $\mathrm{r}: 1.29)$. https://doi.org/10.1524/ract.2002.90.9-11_2002.74'

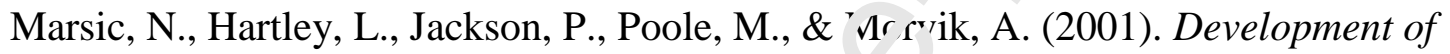
hydrogeological modelling tools based on $T_{i} A_{1 .}{ }^{n}$ ¿U. Swedish Nuclear Fuel and Waste Management Company (SKB), R-repo $t$, , $^{\prime} \mathrm{U}^{\prime} \cdot 49$. Stockholm.

McGrath, P. F., \& Hooton, R. D. (1996). Influ nce of voltage on chloride diffusion coefficients from chloride migration tests. Cemer ${ }^{*}$ and Concrete Research, 26(8), 1239-1244. https://doi.org/https://doi.org/10 10 1, "IJ008-8846(96)00094-4

Mitchell, J. K. (1993). Fundamen ‘ls in Soil Behaviour. John Wiley \& Sons Inc. New York.

Mitchell, J. K., \& Soga, K. (20七5). Fundamentals of soil behavior. John Wiley \& Sons Inc. (3rd ed.). New York.

Möri, A., Mazurek, M., ^rnìd, M., Siegesmund, S., Vollbrecht, A., Ota, K., ... Bühler, C. (2003). The Nagra II /C in situ study of safety relevant radionuclide retardation in fractured crystalline rock: $I V$. The in situ study of matrix porosity in the vicinity of a waterconducting fracture. National Cooperative for the Disposal of Radioactive Waste (Nagra), Technical report, 00-08. Wettingen.

Nebauer, E., Süptitz, P., \& Willert, I. (1977). Determination of the charge of migrating impurities from electrodiffusion profiles: The system a-As2Se3:Cu. Physica Status Solidi (A), 43(2), 451-458. https://doi.org/10.1002/pssa.2210430211

Neretnieks, I. (1980). Diffusion in the rock matrix: An important factor in radionuclide retardation? Journal of Geophysical Research: Solid Earth, 85(B8), 4379-4397. https://doi.org/10.1029/JB085iB08p04379

Nilsson, K., Byegård, J., Selnert, E., Widestrand, H., Höglund, S., \& Gustafsson, E. (2010). Äspö 
Hard Rock Laboratory: Long Term Sorption Diffusion Experiment (LTDE-SD) - Results from rock sample analyses and modelling. Swedish Nuclear Fuel and Waste Management Company (SKB), R-report, $R$-10-68. Stockholm.

Ohlsson, Y. (2001). Studies of ionic diffusion in crystalline rock. Doctoral dissertation, TRITAKET R130. KTH Royal Institute of Technology, Sweden.

Ohlsson, Y., \& Neretnieks, I. (1997). Diffusion data in granite Recommended values. Swedish Nuclear Fuel and Waste Management Company (SKB),TR- report, TR-97-20. Sweden. Retrieved from http://inis.iaea.org/search/search.aspx?orig_q=RN:29017800

Parkhurst, D., \& Appelo, T. (2000). User's guide to PHREEQC (Version 2)—a computer program for speciation, batch-reaction, one-dimensional tran nort, and inverse geochemical calculations. U.S.Dept. Int., U.S.Geol. Surv., T__'nı.ues of Water-Resources Investigation, Report.

Posiva. (2012). Safety Case for the Disposal of Spent Nucl ar $\div$ el at Olkiluoto-Description of the Disposal System. POSIVA 2012-05. Helsinki.

Puukko, E., Lehto, J., Lindberg, A., \& Voutilainen, M. (2ᄂ ' 8). Electromigration experiments for studying transport parameters and sorption of cesium and strontium on intact crystalline rock. Journal of Contaminant Hydrology, 2.1\%, 1.7.

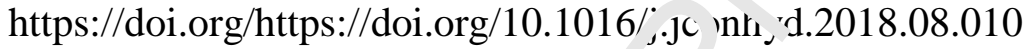

Revil, A. (1999). Ionic diffusivity, electrical cu nductivity, membrane and thermoelectric potentials in colloids and granular pu ous media: A unified model. Journal of Colloid and Interface Science, 212(2), 503-522. ${ }^{*}+\mathrm{ps}: / /$ doi.org/10.1006/jcis.1998.6077

Söderlund, M., Hakanen, M., \& I $\curlywedge$ hto, J. (2016). Sorption of cesium on boreal forest soil I The effect of grain size, organic natter and mineralogy. Journal of Radioanalytical and Nuclear Chemistry, 309(2), 637-64.

Söderlund, M., Virkaren, J., I lolgersson, S., \& Lehto, J. (2016). Sorption and speciation of selenium in boreal i rest soil. Journal of Environmental Radioactivity, 164, 220-231. https://doi.org/http.' doi.org/10.1016/j.jenvrad.2016.08.006

Swedish Nuclear Fuel and Waste Management Company (SKB). (2011). Long-term Safety for the Final Repository for Spent Nuclear Fuel at Forsmark. R-report, R-11-01. Stockholm.

Tachi, Y., Ebina, T., Takeda, C., Saito, T., Takahashi, H., Ohuchi, Y., \& Martin, A. J. (2015). Matrix diffusion and sorption of $\mathrm{Cs}+, \mathrm{Na}+, \mathrm{I}-$ and $\mathrm{HTO}$ in granodiorite: Laboratory-scale results and their extrapolation to the in situ condition. Journal of Contaminant Hydrology, 179, 10-24. https://doi.org/https://doi.org/10.1016/j.jconhyd.2015.05.003

Thunehed, H. (2005). Oskarshamn site investigation: Resistivity measurements and determination of formation factors on samples from KLXO4 and KSHO2. Swedish Nuclear Fuel and Waste Management Company (SKB), P-report, P-05-75. Stockholm. 
Vecernik, P., Havlová, V., \& Löfgren, M. (2013). Application of electromigration method on long rock samples: Determination of migration parameters (Ff,De). In T. Rabung, D.

García, V. Montoya, \& J. Molinero (Eds.), Final Workshop of the Collaborative Project "Crystalline Rock Retention Processes" (pp. 151-161). Karlsruhe: KIT Scientific Publishing.

Vlaev, L. T., \& Genieva, S. D. (2004). Electron Transport Properties of Ions in Aqueous Solutions of Sodium Selenite. Journal of Structural Chemistry, 45(5), 825-831. https://doi.org/10.1007/s10947-005-0064-z

Vomvoris, S., Claudel, A., Blechschmidt, I., \& Müller, H. (2013). The Swiss Radioactive Waste Management Program - Brief History, Status, and Outlook. Journal of Nuclear Fuel Cycle and Waste Technology (Vol. 1). https://doi.org/10.7733/jnfcw . ?013.1.1.9

Wang, J. (2010). High-level radioactive waste disposal in China: 'וp' ate 2010. Journal of Rock Mechanics and Geotechnical Engineering, 2(1), 1-11. https://doi.org/https://doi.org/10.3724/SP.J.1235.2010 00へ̃ 


\section{Author Statement}

Shuo Meng: Conceptualization, Methodology, Software, Validation, Investigation, Data Curation, Writing-Original Draft, Writing-Review \& Editing, Visualization

Xiaodong Li: Conceptualization, Methodology, Software, Formal analysis, Data Curation Marja Siitari-Kauppi: Resources, Supervision, Formal analysis

Longcheng Liu: Methodology, Software, Formal analysis, Resources, Supervision, Project administration, Funding acquisition, Writing-Reviewing \& Editing 


\section{Declaration of interests}

$\bigotimes$ The authors declare that they have no known competing financial interests or personal relationships that could have appeared to influence the work reported in this paper.

$\square$ The authors declare the following financial interests/personal relationships which may be considered as potential competing interests:

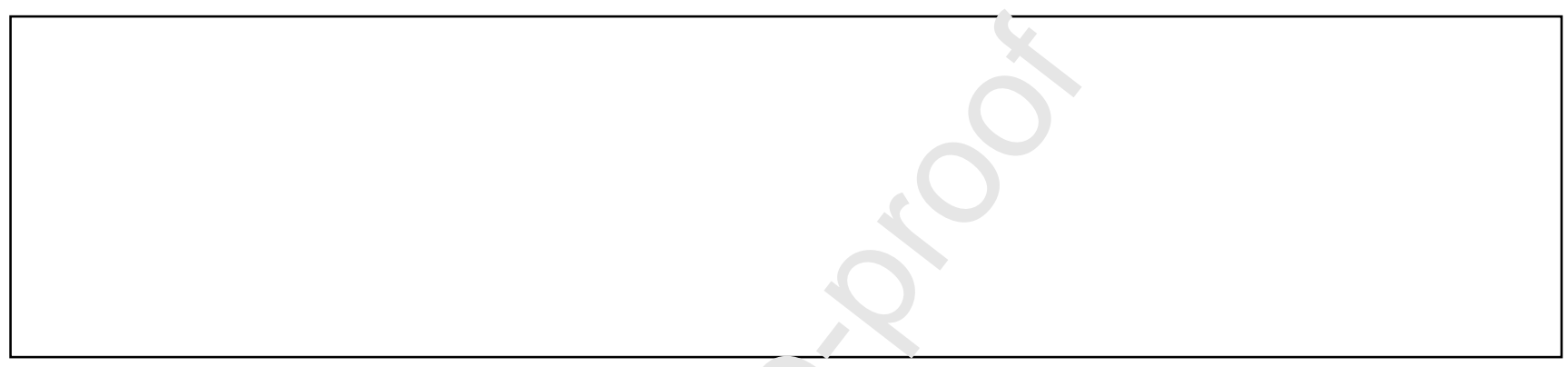




\section{Figure captions:}

Fig. 9: Schematic setup for the electromigration experiments (Löfgren and Neretnieks, 2006).

Fig. 10: The breakthrough curve of iodide with an applied voltage of $2 \mathrm{~V}$ or $4 \mathrm{~V}$ over the rock sample. Markers show the experimental data and the line gives a linear regression of the latetime data.

Fig. 11: The breakthrough curve of selenite with an applied vc tagt of $2 \mathrm{~V}$ or $4 \mathrm{~V}$ over the rock sample. Markers show the experimental data and the line give. a linear regression of the latetime data.

Fig. 12: The $\kappa$ value evaluated from the linear reg es,ion of the late-time breakthrough curve as a function of the applied electric field for bott ld de and selenite, together with the linear regression lines.

Fig. 13: The breakthrough curve of o dis with an applied voltage of $2 \mathrm{~V}$ or $4 \mathrm{~V}$ over the rock sample. Markers show the experir $1 e_{1}{ }^{+}{ }^{2} 1$ data and the line gives the curve-fitted results from the advection-dispersion model.

Fig. 14: The breakthro 'gl. cu' ve of selenite with an applied voltage of $2 \mathrm{~V}$ or $4 \mathrm{~V}$ over the rock sample. Markers show the experimental data and the line gives the curve-fitted results from the advection-dispersion mouel.

Fig. 15: The breakthrough curve of iodide with an applied voltage of $2 \mathrm{~V}$ or $4 \mathrm{~V}$ over the rock sample. Markers show the experimental data and the line gives the curve-fitted results from the reactive transport model. 
Fig. 16: The breakthrough curve of selenite with an applied voltage of $2 \mathrm{~V}$ or $4 \mathrm{~V}$ over the rock sample. Markers show the experimental data and the line gives the curve-fitted results from the reactive transport model. 


\section{Tables:}

Table 9: The model data obtained from electromigration experiments.

\begin{tabular}{|c|c|c|}
\hline \multicolumn{3}{|l|}{ Experimental set-up } \\
\hline $\begin{array}{l}\text { Source/Recipient chamber } \\
\text { volume }\end{array}$ & $\begin{array}{c}\text { Diameter of the source and recipient } \\
\text { chambers }\end{array}$ & Working temperature \\
\hline $152 \mathrm{ml}$ & $5 \mathrm{~cm}$ & $\sim 25^{\circ} \mathrm{C}$ \\
\hline \multicolumn{3}{|l|}{ Rock } \\
\hline Length & Diameter of the rock sample & Porosity of the rock sample \\
\hline $1.12 \mathrm{~cm}$ & $5 \mathrm{~cm}$ & $0.7 \%$ \\
\hline \multicolumn{3}{|l|}{ Background electrolyte } \\
\hline $\mathrm{pH}$ & $\mathrm{NaCl}$ concentration & $\mathrm{NaHCO}_{3}$ concentration \\
\hline$\sim 8.5$ & $0.2 \mathrm{M}$ & $0.002 \mathrm{M}$ \\
\hline \multicolumn{3}{|l|}{ Tracer and other information } \\
\hline $\mathrm{Na}_{2} \mathrm{SeO}_{3} / \mathrm{NaI}$ amount & Effective electroosmotic mobility, & $\begin{array}{c}\text { Electrical potential difference over } \\
\text { rock, } \Delta \psi\end{array}$ \\
\hline $0.1 \mathrm{M}$ & 0 & 2 and $4 \mathrm{~V}$ \\
\hline
\end{tabular}

Table 10: Evaluation of the breakthrou ${ }_{i}^{\text {th }}$ curves obtained with $\mathrm{NaI}$ as the tracer, using the ideal plug-flow model.

\begin{tabular}{|c|c|c|c|c|c|c|}
\hline$\Delta \psi(\mathrm{V})$ & $t_{\mathrm{B}}(\mathrm{hr})$ & $\kappa\left(\mu \mathrm{M} \mathrm{hr}^{-1}\right)$ & $\nu_{\mathrm{m}}^{\mathrm{e}}\left(\mathrm{m}^{2} \mathrm{~s}^{-1}\right)$ & $F_{\mathrm{f}}(-)$ & $\left.\tau_{\mathrm{A}}\right|_{R=1}(\mathrm{hr})$ & $R(-)$ \\
\hline 2.0 & 18.2 & 1.57 & $4.85 \times 10^{-14}$ & $2.38 \times 10^{-5}$ & 64.0 & 1.0 \\
\hline 4.0 & 11.0 & 7.. 1 & $1.13 \times 10^{-13}$ & $5.51 \times 10^{-5}$ & 13.8 & 1.0 \\
\hline \multicolumn{3}{|c|}{ Linear regression $\mathrm{ru}_{3}$} & $8.83 \times 10^{-14}$ & $4.31 \times 10^{-5}$ & & \\
\hline
\end{tabular}

Table 11: Evaluation of the breakthrough curves obtained with $\mathrm{Na}_{2} \mathrm{SeO}_{3}$ as the tracer, using the ideal plug-flow model.

\begin{tabular}{ccccccc}
\hline$\Delta \psi(\mathrm{V})$ & $t_{\mathrm{B}}(\mathrm{hr})$ & $\kappa\left(\mu \mathrm{M} \mathrm{hr}^{-1}\right)$ & $D_{\mathrm{m}}^{\mathrm{e}}\left(\mathrm{m}^{2} \mathrm{~s}^{-1}\right)$ & $F_{\mathrm{f}}(-)$ & $\left.\tau_{\mathrm{A}}\right|_{R=1}(\mathrm{hr})$ & $R(-)$ \\
\hline 2.0 & 28.8 & 0.72 & $1.11 \times 10^{-14}$ & $1.11 \times 10^{-5}$ & 140.8 & 1.0 \\
4.0 & 22.4 & 4.21 & $3.26 \times 10^{-14}$ & $3.26 \times 10^{-5}$ & 23.9 & 1.0 \\
\multicolumn{2}{c}{ Linear regression results } & $2.54 \times 10^{-14}$ & $2.54 \times 10^{-5}$ & & \\
\hline
\end{tabular}


Table 12: Evaluation of the breakthrough curves obtained with $\mathrm{NaI}$ as the tracer, using the advection-dispersion model.

\begin{tabular}{cccccc}
\hline$\Delta \psi(\mathrm{V})$ & $D^{\mathrm{e}}\left(\mathrm{m}^{2} \mathrm{~s}^{-1}\right)$ & $\varepsilon_{\mathrm{TS}} R(-)$ & $D_{\mathrm{m}}^{\mathrm{e}}\left(\mathrm{m}^{2} \mathrm{~s}^{-1}\right)$ & $F_{\mathrm{f}}(-)$ & $R(-)$ \\
\hline 2.0 & $3.66 \times 10^{-13}$ & 0.007 & $1.09 \times 10^{-13}$ & $5.34 \times 10^{-5}$ & 1.0 \\
4.0 & $6.95 \times 10^{-13}$ & 0.007 & $1.21 \times 10^{-13}$ & $5.96 \times 10^{-5}$ & 1.0 \\
& Linear regression results & $1.15 \times 10^{-13}$ & $5.61 \times 10^{-5}$ & \\
\hline
\end{tabular}

Table 13: Evaluation of the breakthrough curves obtained with $\mathrm{Na}_{2} \mathrm{SeO}_{3}$ as the tracer, using the advection-dispersion model.

\begin{tabular}{|c|c|c|c|c|c|}
\hline$\Delta \psi(\mathrm{V})$ & $D^{\mathrm{e}}\left(\mathrm{m}^{2} \mathrm{~s}^{-1}\right)$ & $\varepsilon_{\mathrm{TS}} R(-)$ & $D_{\mathrm{m}}^{\mathrm{e}}\left(\mathrm{m}^{2} \mathrm{~s}^{-1}\right)$ & $F(-)$ & $R(-)$ \\
\hline 2.0 & $3.23 \times 10^{-13}$ & 0.007 & $2.87 \times 10^{-14}$ & {$\left[.^{7} \overline{\lambda i v}^{-5}\right.$} & 1.0 \\
\hline 4.0 & $5.64 \times 10^{-13}$ & 0.007 & $3.14 \times 10^{-14}$ & $\because 10 \times 10^{-5}$ & 1.0 \\
\hline \multicolumn{3}{|c|}{ Linear regression results } & $4.48 \times 10^{-14}$ & $4.48 \times 10^{-5}$ & \\
\hline
\end{tabular}

Table 14: Evaluation of the breakthrough cur e $\mathrm{o}^{\mathrm{l}}$ tained with $\mathrm{NaI}$ as the tracer, using the reactive transport model.

\begin{tabular}{|c|c|c|c|c|c|}
\hline$\Delta \psi(\mathrm{V})$ & $D^{\mathrm{e}}\left(\mathrm{m}^{2} \mathrm{~s}^{-1}\right)$ & $\varepsilon_{\mathrm{TS}} R(-)$ & $D_{\mathrm{m}}^{\mathrm{e}}\left(\mathrm{m}^{2} \mathrm{~s}^{-1}\right)$ & $F_{\mathrm{f}}(-)$ & $R(-)$ \\
\hline 2.0 & $3.83 \times 10^{-13}$ & $0.00 \bar{\prime}$ & $1.15 \times 10^{-13}$ & $5.62 \times 10^{-5}$ & 1.0 \\
\hline 4.0 & $7.83 \times 10^{-13}$ & $\left(0^{\prime} j\right)$ & $1.36 \times 10^{-13}$ & $6.67 \times 10^{-5}$ & 1.0 \\
\hline \multicolumn{3}{|c|}{ Linear regression $\mathrm{esu}^{1+\mathrm{s}}$} & $1.24 \times 10^{-13}$ & $6.06 \times 10^{-5}$ & \\
\hline
\end{tabular}


Table 15: Evaluation of the breakthrough curves obtained with $\mathrm{Na}_{2} \mathrm{SeO}_{3}$ as the tracer, using the reactive transport model.

\begin{tabular}{cccccc}
\hline$\Delta \psi(\mathrm{V})$ & $D^{\mathrm{e}}\left(\mathrm{m}^{2} \mathrm{~s}^{-1}\right)$ & $\varepsilon_{\mathrm{TS}} R(-)$ & $D_{\mathrm{m}}^{\mathrm{e}}\left(\mathrm{m}^{2} \mathrm{~s}^{-1}\right)$ & $F_{\mathrm{f}}(-)$ & $R(-)$ \\
\hline 2.0 & $1.73 \times 10^{-13}$ & 0.007 & $3.83 \times 10^{-14}$ & $3.83 \times 10^{-5}$ & 1.0 \\
4.0 & $3.76 \times 10^{-13}$ & 0.007 & $4.05 \times 10^{-14}$ & $4.05 \times 10^{-5}$ & 1.0 \\
& Linear regression results & $3.37 \times 10^{-14}$ & $3.37 \times 10^{-5}$ & \\
\hline
\end{tabular}

Table 16: Summary of the results obtained from analysis of the breakthrough curves for both iodide and selenite tracers.

\begin{tabular}{|c|c|c|c|c|}
\hline \multirow[b]{2}{*}{ Model applied } & \multicolumn{2}{|c|}{ Iodide } & \multicolumn{2}{|c|}{ Selenite } \\
\hline & $D_{\mathrm{m}}^{\mathrm{e}}\left(10^{-14} \mathrm{~m}^{2} \mathrm{~s}^{-1}\right)$ & $F_{\mathrm{f}}\left(10^{-5}\right)$ & $\nu_{\mathrm{m}}\left(\mathrm{Iv}^{4} \mathrm{~m}^{2} \mathrm{~s}^{-1}\right)$ & $F_{\mathrm{f}}\left(10^{-5}\right)$ \\
\hline Ideal plug-flow model & $8.33 \pm 3.25$ & $4.06 \pm 1.59$ & $3.30 \pm 0.89$ & $2.30 \pm 0.89$ \\
\hline Advection-dispersion model & $11.5 \pm 0.60$ & $5.61 \pm 0^{n n}$ & $3.50 \pm 0.86$ & $3.50 \pm 0.86$ \\
\hline Reactive transport model & $12.5 \pm 1.05$ & $6.11 \pm v \cdot{ }^{5} 1$ & $3.75 \pm 0.35$ & $3.75 \pm 0.35$ \\
\hline Data reported in literature & $1.0 \sim 46.0$ & $1.0 \sim-0.0$ & $1.0 \sim 10.0$ & $1.0 \sim 20.0$ \\
\hline
\end{tabular}




\section{Highlights}

- An advection-dispersion model was developed for electromigration experiments.

- A derived semi-analytical solution was used to analyze the experimental results.

- The estimated parameters of tracers make an agreement with literature values.

- A reactive transport model was developed, considerin s a ${ }^{\top}$ ucous chemistry effect.

- Advection-dispersion model works equally welı is t e reactive transport model. 